\title{
Protective Antibodies Against Human Parainfluenza Virus Type 3 (HPIV3) Infection
}

\author{
Jim Boonyaratanakornkit ${ }^{1}$, Suruchi Singh ${ }^{1}$, Connor Weidle ${ }^{1}$, Justas Rodarte ${ }^{1}$, Ramasamy \\ Bakthavatsalam ${ }^{2}$, Jonathan Perkins ${ }^{3}$, Guillaume B.E. Stewart-Jones ${ }^{4}$, Peter D. Kwong ${ }^{4}$, Andrew T. \\ McGuire $^{1}$, Marie Pancera ${ }^{1,4}$, and Justin J. Taylor ${ }^{1^{*}}$

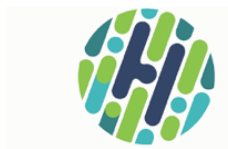 \\ FRED HUTCH \\ CURES START HERE ${ }^{\oplus}$
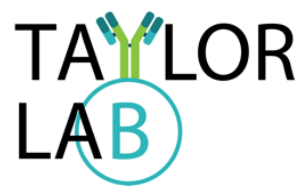 \\ ${ }^{1}$ Vaccine and Infectious Disease Division, Fred Hutchinson Cancer Research Center, Seattle, WA, USA \\ ${ }^{2}$ Department of Surgery, University of Washington, Seattle, WA, USA \\ ${ }^{3}$ Department of Otolaryngology, University of Washington, Seattle, WA, USA \\ ${ }^{4}$ Vaccine Research Center, National Institute of Allergy and Infectious Diseases, National Institutes of Health, \\ Bethesda, MA, USA \\ *Correspondence: jboonyar@fredhutch.org / @JimBoonyaratana, jtaylor3@,fredhutch.org / @,JustinTaylorLab
}

\begin{abstract}
Human parainfluenza virus type III (HPIV3) is a common respiratory pathogen that afflicts children and can be fatal in vulnerable populations, including the immunocompromised. Unfortunately, an effective vaccine or therapeutic is not currently available, resulting in tens of thousands of hospitalizations per year. In an effort to discover a protective antibody against HPIV3, we screened the B cell repertoires from peripheral blood, tonsils, or spleen from healthy children and adults. These analyses yielded five monoclonal antibodies that potently neutralized HPIV3 in vitro. These HPIV3 neutralizing antibodies targeted two non-overlapping epitopes of the HPIV3 F protein, with most targeting the apex. Importantly, prophylactic administration of one of these antibodies, named PI3-E12, resulted in potent protection against HPIV3 infection in cotton rats. Additionally, PI3-E12 could also be used therapeutically to suppress HPIV3 in immunocompromised animals. These results demonstrate the potential clinical utility of PI3-E12 for the prevention or treatment of HPIV3 in both immunocompetent and immunocompromised individuals.
\end{abstract}

\section{INTRODUCTION}

HPIV3 is a common cause of respiratory illness in infants and children. Over 11,000 hospitalizations per year in the US occur for fever or acute respiratory illness due to HPIV $3^{1}$. HPIV3, like respiratory syncytial virus (RSV), infects early in life and frequently causes severe bronchiolitis and pneumonia in infants under six months of age who are unable to mount a robust antibody response $\mathrm{e}^{2,3}$. HPIV3 is also an important cause of mortality, morbidity, and health care costs in other vulnerable populations, such as immunocompromised hematopoietic stem cell transplant (HCT) recipients ${ }^{4}$. Up to a third of HCT recipients acquire a respiratory viral infection within six months of transplant ${ }^{5-11}$. In up to a third of those patients, the virus progresses from the upper to the lower respiratory tract ${ }^{6,9}$. Once the virus gains a foothold in the lower tract, little can be done for most viruses beyond supportive care; up to $40 \%$ of patients with lower tract disease die within three months. HPIV3 is an important cause of serious respiratory viral infections after HCT, with a cumulative incidence of $18 \%$ post-transplant at our center $^{5,12-14}$. In the absence of any vaccine or therapy, there is significant need for preventive and therapeutic interventions against HPIV3.

Neutralizing monoclonal antibodies have been correlated with protection against several respiratory viruses, including RSV and influenza ${ }^{15-19}$. The monoclonal antibody palivizumab is a humanized antibody targeting the Fusion $(\mathrm{F})$ protein of RSV and was licensed for use as immunoprophylaxis to prevent severe disease in high-risk infants ${ }^{20}$. The $\mathrm{F}$ protein of $\mathrm{RSV}$ is an essential surface glycoprotein and therefore a major neutralizing antibody target. As a class I fusion protein, $\mathrm{F}$ mediates viral entry by transitioning between a metastable prefusion (preF) conformation and a stable postfusion (postF) conformation. Since preF is the major conformation on infectious virus, antibodies to preF are the most potent at neutralizing virus, whereas antibodies targeting postF generally are not ${ }^{21,22}$. Similar to RSV, the F protein of HPIV3 also adopts preF and postF conformations ${ }^{23,24}$. HPIV3 $\mathrm{F}$ was recently stabilized in the preF conformation and induced higher serum neutralizing titers than the HPIV3 postF 
conformation $^{25}$. In an effort to isolate monoclonal antibody candidates for prevention and therapy, we developed a high-throughput screening strategy that enabled the rapid selection and testing of human HPIV3 preF-specific B cells for the ability to neutralize HPIV3. We applied this method to isolate several potent neutralizing monoclonal antibodies, characterized their binding, and tested one of these antibodies in an in vivo challenge model.

\section{RESULTS}

\section{Identification and isotype of HPIV3-specific B cells} within the human $B$ cell repertoire

We biotinylated the HPIV3 F protein in either the preF or postF conformation and mixed each with fluorochrome-labeled streptavidin. We then enriched for HPIV3 preF- and postF-binding B cells using magnetic microbeads conjugated to antibodies targeting the fluorochrome. Using this approach, we identified B cells that specifically bound the preF conformation and not the postF conformation or fluorochrome-labeled
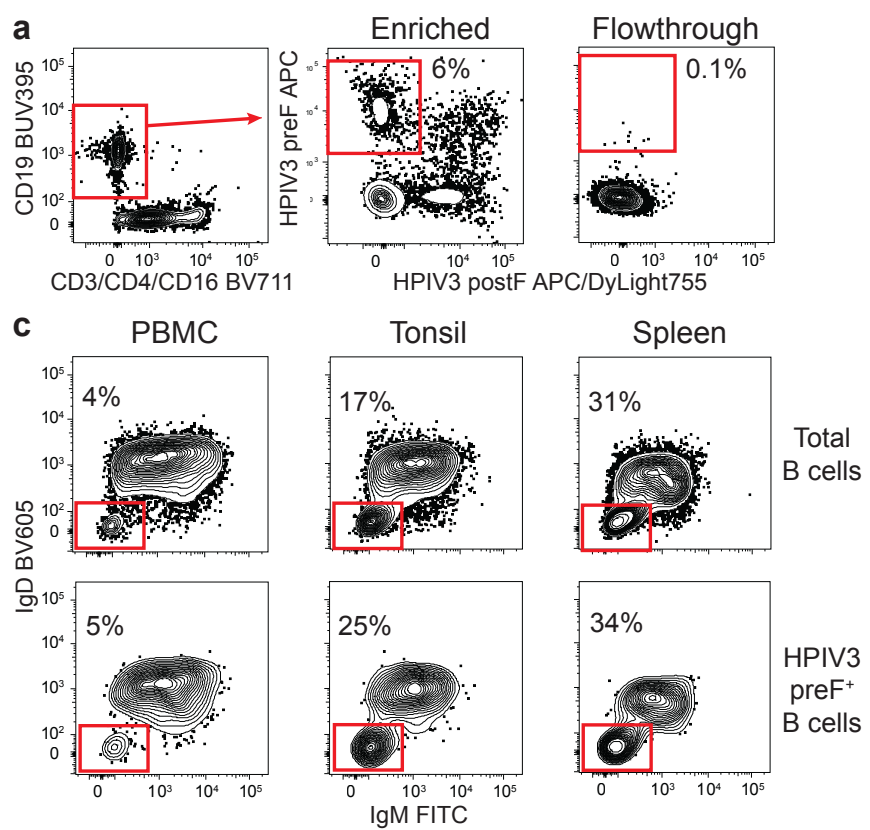

Figure 1. Screening human PBMCs, tonsils, and spleens for HPIV3-specific B cells. (a) HPIV3-specific B cells were labeled with APC-conjugated streptavidin tetramers of biotinylated HPIV3 prefusion (preF) protein followed by magnetic enrichment using microbeads against APC. Representative flow cytometry plot of enriched HPIV3-specific B cells after gating on live (fixable viability dye negative), $\mathrm{CD} 3 / \mathrm{CD} 14 / \mathrm{CD} 16^{-}$, and $\mathrm{CD} 19^{+} \mathrm{B}$ cells. Cells in the red box of the enriched fraction are $\mathrm{B}$ cells that bind the preF but not postfusion (postF) conformation of the HPIV3 F protein. The percentage is of total cells shown in the flow plot. (b) The frequency HPIV3 preF-specific B cells in human PBMCs, tonsils, and spleen. (c) Representative flow cytometry plots of isotype switched $\left(\mathrm{IgM}^{-} / \mathrm{IgD}^{-}\right) \mathrm{B}$ cells in PBMCs, tonsils and spleen. (d-e) The frequency of switched (IgM-/IgD $)$ total and HPIV3 preF-specific B cells as a percentage of total $\mathrm{B}$ cells in $\mathrm{PBMC}$, tonsils, and spleen. $\mathrm{N}=4$ donors for PBMCs and tonsils and $\mathrm{N}=2$ for spleens with each data point representing the average of 2-4 replicates per donor. Asterisks in $\mathbf{d}$ and $\mathbf{e}$ indicate $P<0.05$ by t-test compared to PBMC. b
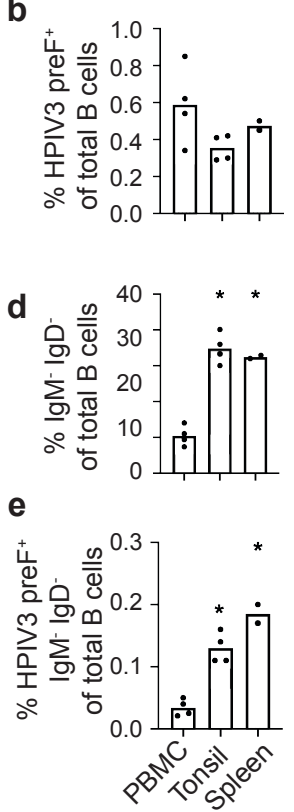

streptavidin using flow cytometry (Fig. 1a). Since the to assess samples of peripheral blood, tonsils spleens from unmatched donors, since these secondary lymphoid organs might be enriched for B cells that had undergone affinity maturation for binding HPIV3. Overall, we found $0.20-1.07 \%$ of B cells in these tissues bound HPIV3 preF (Fig. 1b). The overall frequency of $\mathrm{IgM}^{-} \mathrm{IgD}^{-}$isotype-switched $\mathrm{B}$ cells was significantly increased in the spleen and tonsils (Fig. 1c, d), as was

Binding and neutralization of HPIV3 within the man cell repertoire

preF-binding $\mathrm{B}$ cells identified by flow cytometry produced antibodies that could bind and neutralize HPIV3. For this we sorted 92 HPIV3 preF-binding B cells from two donor PBMC samples into individual wells of a 96-well plate and obtained 25 paired heavy and light chain sequences (Supplemental Table 1). We expressed all 25 as monoclonal antibodies and confirmed binding to purified HPIV3 preF for $100 \%(25 / 25)$ of antibodies using Bio-Layer Interferometry (BLI) (Fig. 2a), highlighting the specificity of our approach. Amongst this group, two monoclonal antibodies, PI3-E12 and PI3-C9, bound with high apparent affinities $\left(\mathrm{K}_{\mathrm{D}}\right)$ to HPIV3 preF, $1 \times 10^{-12} \mathrm{M}$ and $4.0 \times 10^{-8} \mathrm{M}$, respectively (Fig. 2b). The higher apparent affinity of PI3-E12 compared to PI3-C9 for HPIV3 preF resulted from slower dissociation, $1 \times 10^{-}$ $7 / \mathrm{s} \quad$ versus $2.7 \times 10^{-4} / \mathrm{s}$, respectively (Fig. 2c, d). Correspondingly, PI3-E12, but not PI3-C9, was capable of neutralizing live virus in vitro (Fig. 2e). Together, these data indicated that a low frequency of HPIV3 preF tetramerbinding $\mathrm{B}$ cells express highaffinity antibodies capable of neutralizing HPIV3. 

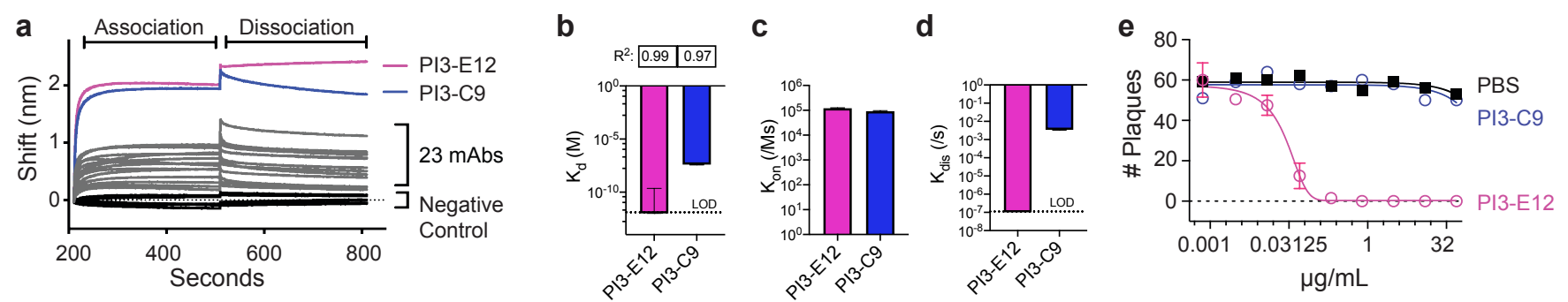

Figure 2. Identification of a potent HPIV3-neutralizing antibody from HPIV3 preF-binding B cells. (a) Bio-Layer Interferometry (BLI) measurements of association and dissociation between HPIV3 preF and 25 monoclonal antibodies (mAbs) cloned directly from individually sorted HPIV3 preF-binding B cells. (b) Apparent affinity $\left(\mathrm{K}_{\mathrm{D}}\right)$, (c) on rate ( $\left.\mathrm{K}_{\mathrm{on}}\right)$ and $(\mathbf{d})$ dissociation rate $\left(\mathrm{K}_{\text {dis }}\right)$. Binding kinetics of the PI3-E12 and PI3-C9 mAbs with HPIV3 preF at 0.5, 0.25, 0.125, and 0.0625 $\mu \mathrm{M}$ measured by BLI. LOD stands for limit of detection. $\mathrm{R}^{2}$ represents the coefficient of determination. (e) Plaque reduction neutralization test of the PI3-E12 mAb ( N=2 per group). Error bars in b-e represent standard deviation.

To focus upon B cells producing neutralizing antibodies, we modified our assay to sort individual B cells onto irradiated 3T3 feeder cells expressing CD40L, IL-2, and IL-21 to allow for higher throughput screening of culture supernatants for neutralization prior to antibody cloning, as described ${ }^{27}$. In general, over half of sorted B cells and $87 \%$ of sorted $\mathrm{IgD}^{-} \mathrm{B}$ cells produced antibody levels detectable by ELISA (Fig. 3a). We applied this assay to stimulate single HPIV3 preF-binding $\mathrm{B}$ cells and excluded IgDexpressing cells since these cells would be the least likely to have undergone the somatic hypermutation and affinity maturation necessary for potent neutralization. Using this approach, we found that $14 \%$ of IgD ${ }^{-}$HPIV 3 preF-binding $\mathrm{B}$ cells sorted from tonsils produced HPIV3 neutralizing antibodies, as compared to 5\% from the spleen and 2\% from peripheral blood (Fig. 3b).

From these cultures we cloned four additional HPIV3 neutralizing monoclonal antibodies named PI3A3, PI3-B5, PI3-A10, and PI3-A12 (Fig. 3c). Of these, PI3-A12 had the highest apparent binding affinity to HPIV3 preF, and its affinity was comparable to PI3-E12 (Fig. 3d). The neutralization potency of these antibodies ranged from 7.0 to $61.4 \mathrm{ng} / \mathrm{mL}$ (Fig. 3c). Each neutralizing monoclonal antibody used different immunoglobulin heavy and light chain alleles except for PI3-A3 and PI3-B5, which both utilized the kappa allele 1-5*03 (Supplemental Table 2). None of the alleles matched those of the previously described HPIV3 antibody PIA $174^{25}$. The similarity to germ-line sequences of the variable genes from these neutralizing antibodies ranged from 90-97\% (Supplemental Table 2). All of these newly described antibodies bound strongly to the preF conformation without any detectable binding to the postF conformation (Fig. 3d, e), as expected given the exclusion of $\mathrm{B}$ cells binding postF during the sort. In contrast, the previously described antibody PIA174 bound weakly to the postF conformation in addition to strong preF binding (Fig. 3e). In anticipation of administering these antibodies in vivo, we confirmed that none bound to permeabilized HEp-2 cells (Fig. 3f), a common assessment of autoreactivity ${ }^{28,29}$.

We next performed cross-competition binding experiments to gauge the antigenic sites on HPIV3 preF allowing for neutralization. Three of these five new neutralizing monoclonal antibodies (PI3-E12, -A3, and -B5) fully competed with each other and the previously described antibody PIA174 (Fig. 4a). PI3-A10 also competed with this group, but only partially with PI3E12 (Fig. 4a). Based on the known binding site of PIA174, this antigenic site is likely located at the apex of HPIV3 preF $^{25}$. We propose calling this antigenic site $\varnothing$ on HPIV3 preF for consistency, since the apices of RSV and HMPV preF are also called antigenic site $\varnothing^{30,31}$. The fifth neutralizing monoclonal, PI3-A12, only weakly competed with PI3-A10 and not at all with the others, suggesting the presence of an antigenic site vulnerable to neutralization by antibodies outside of antigenic site $\varnothing$ (Fig. 4a).

We performed negative stain electron microscopy (nsEM) of PI3-E12 Fab, PI3-A12 F $\mathrm{ab}_{\mathrm{ab}}$, and PI3-C9 $\mathrm{F}_{\mathrm{ab}}$ in complex with HPIV3 preF (Fig. $\mathbf{4 b}$, c) to confirm the binding location of these antibodies. Although we could form a complex by size exclusion chromatography (SEC) of HPIV3 preF with PI3-C9 $\mathrm{F}_{\mathrm{ab}}$, nsEM did not show bound PI3-C9 $\mathrm{F}_{\mathrm{ab}}$ molecules. 2D classifications and $3 \mathrm{D}$ reconstruction indicated that PI3-A12 $\mathrm{F}_{\mathrm{ab}}$ was bound to the side of HPIV3 preF in a 3:1 ratio, confirming that its epitope does not overlap with that of previously described PIA174 antibody and defining a new site of neutralization on HPIV3 preF (Fig. 4b). Of note, this site is reminiscent of site $\mathrm{V}$ on $\mathrm{RSV} \mathrm{F}^{22}$. As predicted earlier, 2D classifications and 3D reconstruction showed that the PI3-E12 $\mathrm{F}_{\mathrm{ab}}$ bound at the apex of HPIV3 preF in a 1:1 ratio ( $\mathrm{F}_{\mathrm{ab}}$ :trimer). However, PI3-E12 $\mathrm{F}_{\mathrm{ab}}$ appears to bind HPIV3 preF with a different angle of approach compared to PIA174 (Fig. 4c). We obtained a $5.4 \AA$ cryo-EM structure of the 

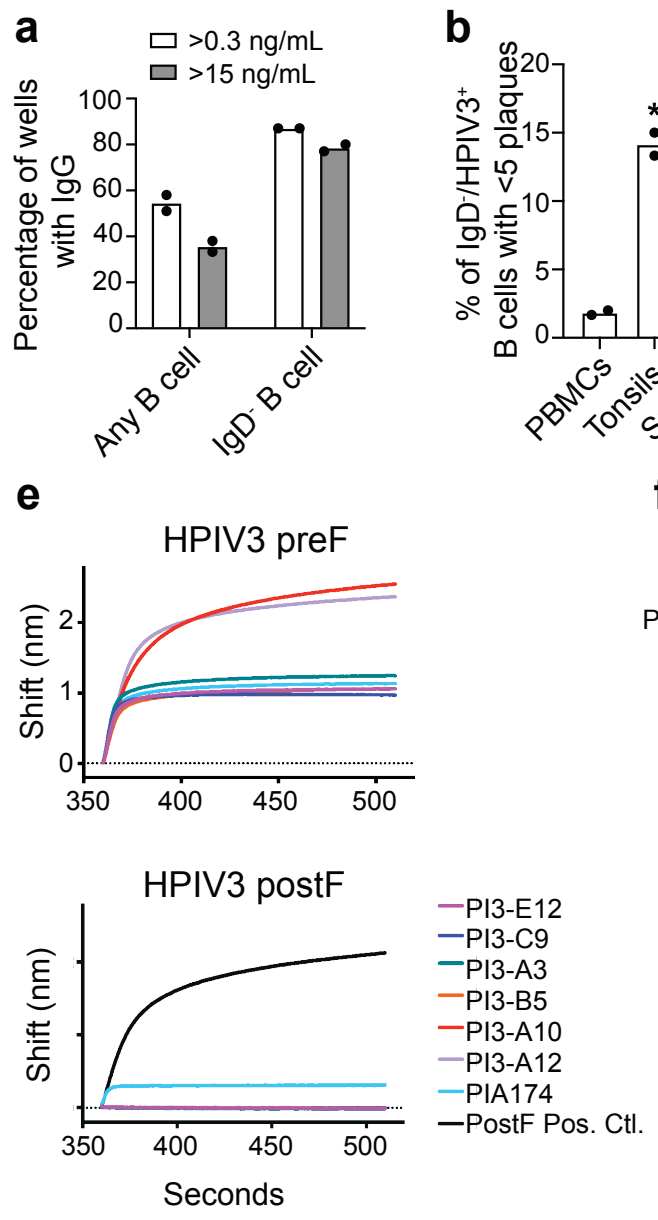
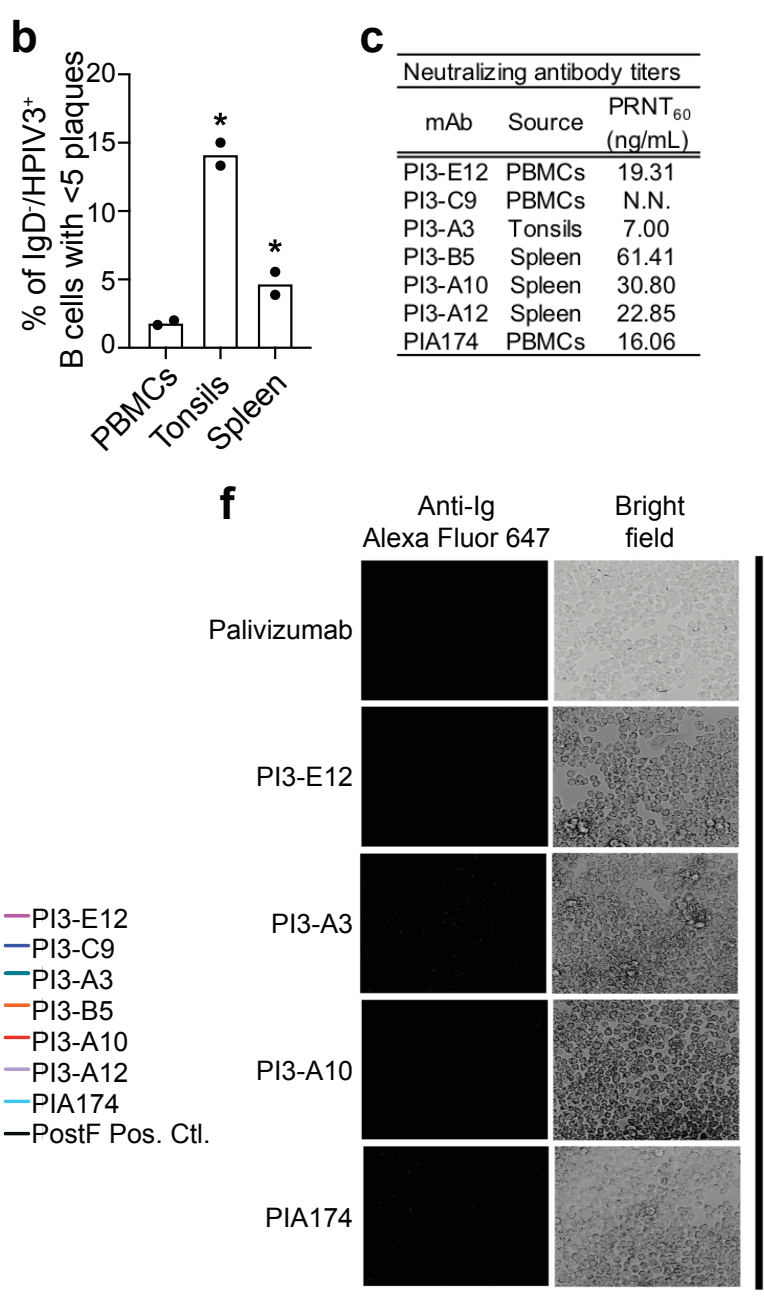
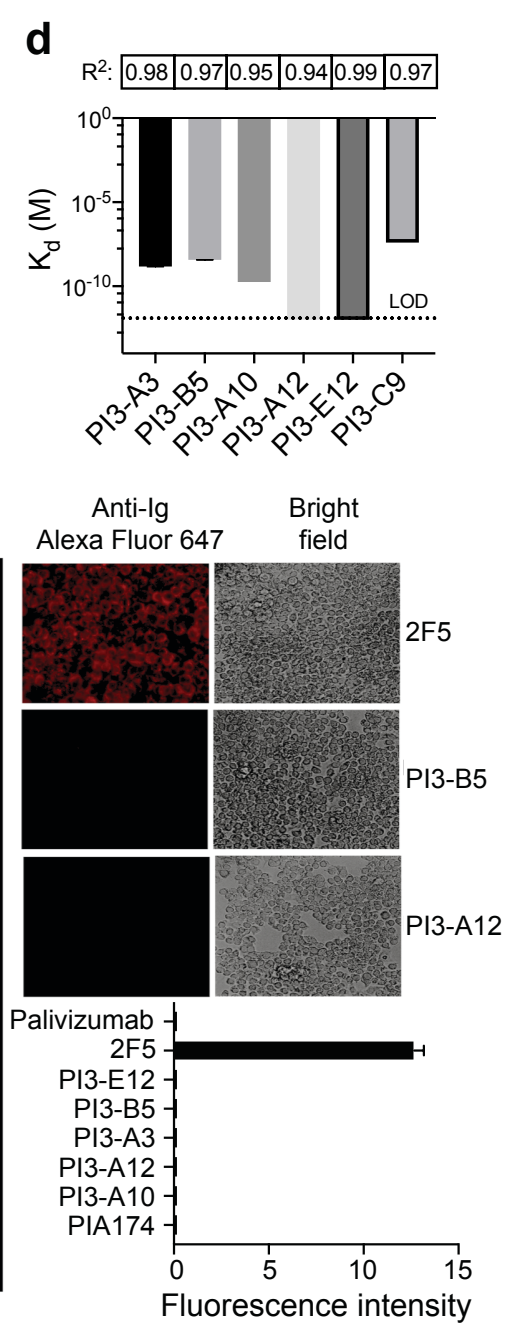

Figure 3. Higher throughput screening human PBMCs, tonsils, and spleen for B cells capable of producing neutralizing antibodies against HPIV3. a) Detection of IgG by ELISA in supernatant from total $\mathrm{B}$ cells and $\operatorname{IgD}^{-} \mathrm{B}$ cells of unknown specificities ( $\mathrm{N}=2$ donors) individually sorted and expanded on irradiated $\mathrm{IL}-21^{+} / \mathrm{IL}-2^{+} / \mathrm{CD} 40 \mathrm{~L}^{+} 3 \mathrm{~T} 3$ feeder cells. (b) Plaque reduction neutralization screen of supernatant from HPIV3 preF-specific B cells individually sorted and expanded on feeder cells. $\mathrm{N}=2$ donors in each group with a total of 120 cells from PBMC, 120 cells from tonsils, 1,235 cells from spleen. (c) Neutralizing titers of HPIV3-specific monoclonal antibodies were determined by $60 \%$ plaque reduction neutralization tests on Vero cells using GFP-labeled HPIV3. (d) Apparent affinity $\left(\mathrm{K}_{\mathrm{d}}\right)$ of antibody binding with HPIV3 preF at $0.5,0.25,0.125$, and $0.0625 \mu \mathrm{M}$ were measured by BLI. LOD stands for limit of detection. Error bars represent standard deviation. $\mathrm{R}^{2}$ represents the coefficient of determination. Penta-HIS probes were loaded with either the (e) preF or postF conformation of HPIV3 F. Association with each mAb was then measured by BLI. All measurements are normalized against a negative control antibody. The positive control antibody is a human mAb known to bind HPIV3 postF. (f) Antinuclear antibody assay in HEp-2 cells using mAbs targeting HPIV3 preF. Binding was detected using a secondary Alexa Fluor 647 (AF647)-conjugated goat anti-human antibody. The mAb palivizumab was used as a negative control and 2F5 as a positive control for autoreactivity. The average fluorescence intensity was calculated from two independent experiments and error bars represent standard deviation.

PI3-E12 $F_{a b}$ in complex with HPIV3 preF (Fig. 4d). Using the previously solved HPIV3-preF structure (PDB ID 6MJZ) and a $2.1 \AA$ structure of PI3-E12 $\mathrm{F}_{\mathrm{ab}}$ that we obtained using X-ray crystallography (Fig. 4d \& Supplemental Tables 3 and 4 and Fig. S1), we were able to fit the coordinates in our low resolution cryoEM map. The structure confirmed the slightly different angle of approach and that all the CDRs interact with the different protomers in a non-symmetrical manner. We superimposed the structure of HPIV3 preF (root mean standard deviation: $1.7 \mathrm{~A}^{2}$ ) bound to PI3-E12 $\mathrm{F}_{\mathrm{v}}$ or PIA174 (Fig. 4e) which confirmed that their epitopes overlapped. Additionally, PI3-E12 used its longer CDRL1 to make quaternary contacts with 2 protomers 
a

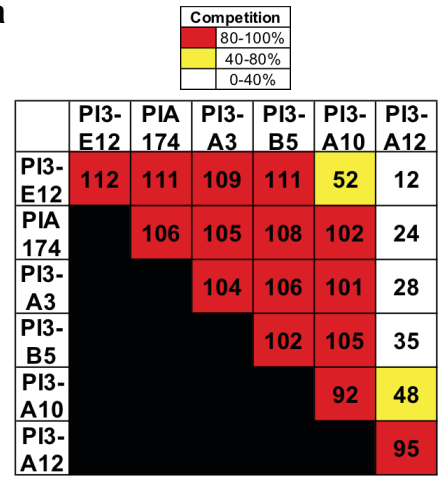

b

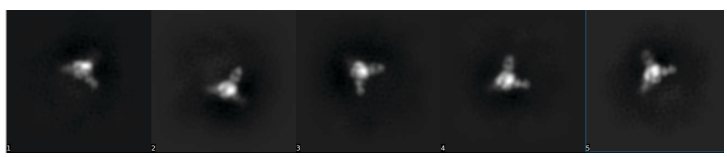

C

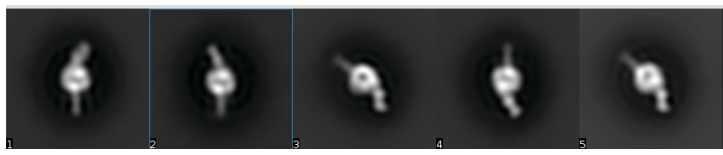

$\mathbf{f}$
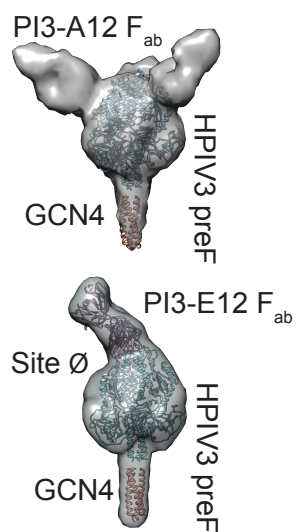

d

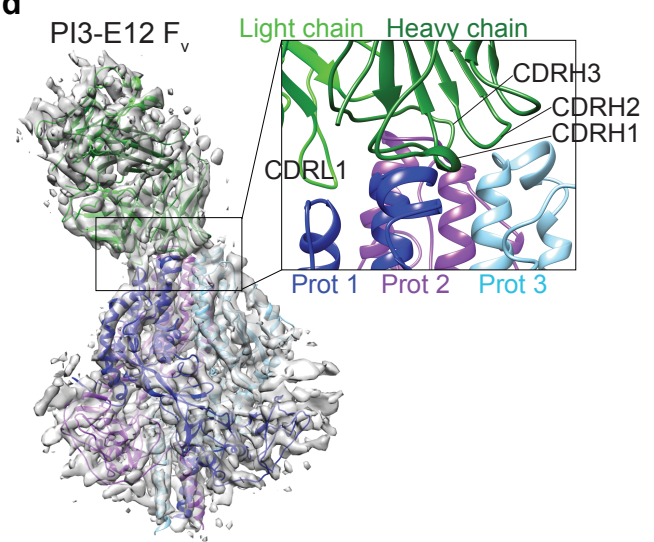

e

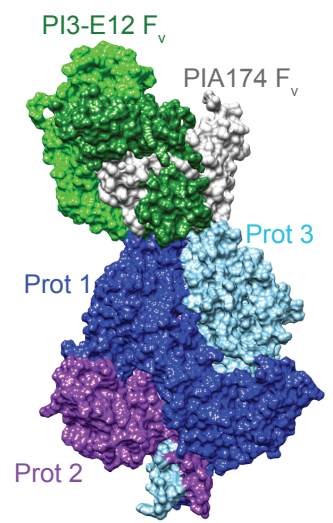

$\underline{\mathrm{CDRH} 3}$

PI3-E12 ARA K WG TMGRIGA P P T I YDH PIA174 AR - - - Q Q VK SGW F VQP FDY

$\underline{\text { CDRL1 }}$

PI3-E12 QS L L Q S NGNNY PI3-E12 (gl) Q S L L H S N G Y NY

PIA174 QA I A - - - - NY

PIA174 (gl) Q S I S - - - SY

Figure 4. Structural analysis of monoclonal antibodies against HPIV3 preF. (a) Epitope binning of mAbs using the Octet system. Penta-HIS probes were coated with HIS-tagged HPIV3 preF. The mAb listed on the left-side of the chart was loaded first onto the coated probe followed by the $\mathrm{mAb}$ listed on the top of the chart. Values represent the level of competition between antibodies for the same binding site on HPIV3 preF. This is expressed as the percent drop in maximum signal of the top $\mathrm{mAb}$ in the presence of the left $\mathrm{mAb}$ compared to the maximum signal of the top $\mathrm{mAb}$ alone. Red boxes represent 80 $100 \%$ competition for the same binding site, yellow boxes represent $40-80 \%$ competition, and white boxes represent $0-40 \%$ competition. (b, c) Negative stain electron microscopy (nsEM) 2D classifications of HPIV3 preF in complex with PI3-A12 $\mathrm{F}_{\mathrm{ab}}(\mathbf{b})$ and PI3-E12 $\mathrm{F}_{\mathrm{ab}}(\mathbf{c})$ with 3D reconstruction. Coordinates of HPIV3 preF trimer (blue, PDB ID 6MJZ), trimeric domain GCN4 (orange, PDB ID 4DME), and crystal structure of PI3-E12 $\mathrm{F}_{\mathrm{ab}}$ (green, this paper) were fitted in the 3D map. (d) CryoEM structure at $5.4 \AA$ resolution of prefusion HPIV3 F bound to PI3-E12 $\mathrm{F}_{\mathrm{v}}$. The complex was most ordered at the core of the HPIV3 $\mathrm{F}$ trimer and at its interface with the PI3-E12 $\mathrm{F}_{\mathrm{v}}$. Insets show antibody-apex interactions. Protomers of the HPIV3 preF trimer are colored dark blue, light blue, and purple. (e) Surface representation of HPIV3 preF bound to PI3-E12 $\mathrm{F}_{\mathrm{v}}$ (green) and PIA174 Fv (grey, PDB ID 6MJZ). (f) Sequence alignment of PI3-E12 and PIA174. Alignment with germline (gl) CDRL1 sequences are also shown with mutations from germline highlighted in red.

whereas the CDRH3 reaches towards the trimer axis and makes quaternary contacts with the three HPIV3 preF protomers (Fig. 4d, f).

Together, our results indicate that the HPIV3 preF apical antigenic site $\varnothing$ is a common target of neutralizing antibodies that can be accessed by antibodies using different gene segments and with different angles of approach.

\section{In vivo protection against HPIV3 infection}

We next investigated the potential clinical utility of PI3E12 in an animal challenge model of HPIV3 infection. Although the human parainfluenza viruses do not replicate in mice, lower respiratory tract pathology and viral replication can be demonstrated in cotton rats infected intranasally with HPIV $3^{26,32}$. The cotton rat model was used in the past to predict not only the efficacy of antibody immunoprophylaxis but also the exact dose of palivizumab, $15 \mathrm{mg} / \mathrm{kg}$, that would be effective against RSV in human infants ${ }^{20}$. Therefore, we adopted a similar experimental design and injected $0.625-5 \mathrm{mg} / \mathrm{kg}$ of PI3-E12 intramuscularly one day prior to intranasal infection of cotton rats with $10^{5} \mathrm{pfu}$ of HPIV3 (Fig. 5a). None of the animals that received PI3-E12 developed significant peribronchiolitis. A trend towards higher histopathologic scores of peribronchiolitis was detected 4 days after infection in 

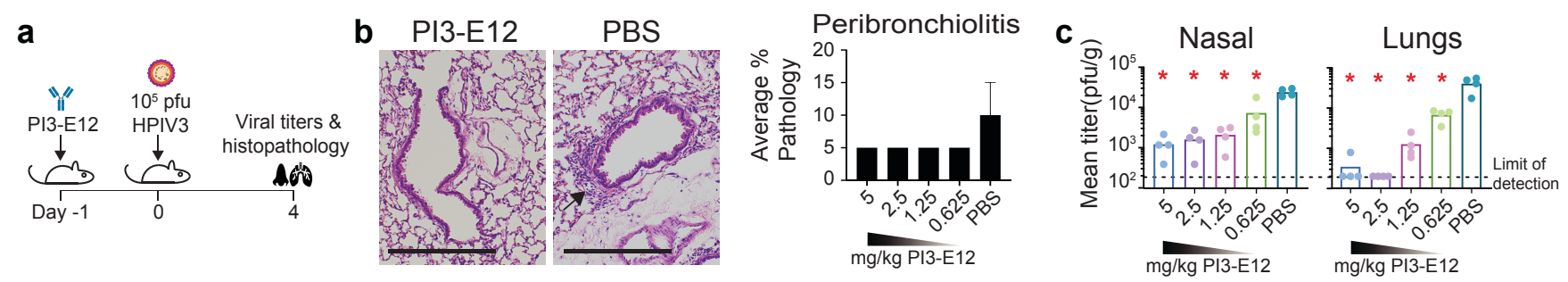

Figure 5. Efficacy of prophylactic and therapeutic administration of the neutralizing HPIV3 mAb PI3-E12 in vivo. (a) Schematic of experiments in which cotton rats were injected intramuscularly with $0.625-5 \mathrm{mg} / \mathrm{kg}$ of PI3-E12 one day prior to intranasal challenge with $10^{5}$ pfu HPIV3 $(\mathrm{N}=4)$. (b) Lung histopathology at day four post-infection with $10^{5}$ PFU of HPIV3. The arrow indicates an area of peri-bronchiolitis. The scale bar represents $2.0 \mathrm{~mm}$. Peribronchiolitis was scored as percent severity (c) HPIV3 titers by plaque assay in nasal and lung homogenates at day four post-infection. (c) Schematic of experiments in which cotton rats were injected intramuscularly with $5 \mathrm{mg} / \mathrm{kg}$ cytoxan every three days for three weeks prior to infection with $10^{5} \mathrm{PFU}$ of HPIV3 with or without $5 \mathrm{mg} / \mathrm{kg}$ PI3-E12 one day later (N=5). (d) HPIV3 titers by plaque assay in nasal and lung homogenates at day four post-infection. Error bars in $\mathbf{b}$ and $\mathbf{d}$ represent standard deviation and asterisks indicate $P<0.05$ by t-test compared to control mice injected with PBS.

control animals that received PBS but this was not statistically significant (Fig. 5b). Consistent with decreased peribronchiolitis, the amount of HPIV3 detected in the lung was reduced $\sim 6$-fold at the lowest tested dose of $0.625 \mathrm{mg} / \mathrm{kg}$ PI3-E12 and was below the limit of detection in $8 / 9$ animals injected with $2.5 \mathrm{mg} / \mathrm{kg}$ or more (Fig. 5c). lungs. More modest reductions in HPIV3 replication in the nose were also detected (Fig. 5c), which was expected given the relatively poor ability of IgG antibodies to enter this compartment ${ }^{33,34}$. Together, the data indicate an $\mathrm{EC}_{50}$ of $0.35 \mathrm{mg} / \mathrm{kg}$ and an $\mathrm{EC}_{99}$ of $1.80 \mathrm{mg} / \mathrm{kg}$ for PI3-E12-mediated prevention of HPIV3 in the lungs.

Since patients receiving cytotoxic therapy for cancer or autoimmune diseases and other immunocompromised groups are at the highest risk for severe disease and mortality due to HPIV 3 infection, we tested the efficacy of PI3-E12 as treatment in immunosuppressed animals. For this we adopted a similar experimental design used to model RSV in immunocompromised cotton rats in which the drug Cytoxan is administered to deplete lymphocytes ${ }^{35-37}$. Animals were treated with $5 \mathrm{mg} / \mathrm{kg}$ of Cytoxan injected every three days for 21 days prior to intranasal infection with $10^{5}$ pfu of HPIV3 (Fig. 6a). Five days after infection, $\sim 10^{4} \mathrm{pfu} / \mathrm{g}$ could be detected in the lungs and nose of control animals that did not receive PI3-E12 (Fig. 6b). In contrast, viral titers were diminished 28fold in the lungs and 2-fold in the nose when $5 \mathrm{mg} / \mathrm{kg}$ of PI3-E12 was injected one day after infection (Fig. 6b).

Together, our data indicates that PI3-E12 can both prevent and treat HPIV3 infection.

\section{CONCLUSIONS}

The ability to isolate neutralizing monoclonal antibodies and to identify their antigenic binding sites has revolutionized our ability to understand, prevent, and treat viral infections, some of which include HIV, Ebola, RSV, influenza, and the newly emerged SARSCoV-2, responsible for the current COVID-19 pandemic ${ }^{38-40}$. One of the goals of this study was to quantify the frequency of B cells capable of producing neutralizing antibodies against HPIV3. We designed our B cell probes and flow cytometry panel to allow the selection of B cells that bind specifically to the preF but not the postF conformation of HPIV3 F protein. Even with this selection strategy, we found that the majority of HPIV3 preF-specific B cells failed to neutralize virus. This is not surprising, since B cells undergo positive selection based on signals that stem from the affinity of binding between their immunoglobulin receptor and cognate antigen, regardless of neutralization $^{41,42}$. In the circulating peripheral blood of

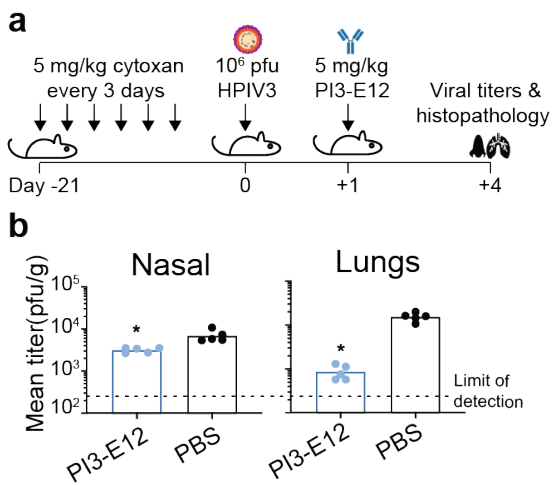

Figure 6. Efficacy of therapeutic administration of the neutralizing HPIV3 mAb PI3-E12 in vivo. (a) Schematic of experiments in which cotton rats were injected intramuscularly $5 \mathrm{mg} / \mathrm{kg}$ cytoxan every three days for three weeks prior to infection with $10^{5}$ PFU of HPIV3 with or without $5 \mathrm{mg} / \mathrm{kg}$ PI3-E12 one day later. $(\mathrm{N}=5)$. (b) HPIV3 titers by plaque assay in nasal and lung homogenates at day four post-infection. Error bars standard deviation and asterisks indicate $P<0.05$ by t-test compared to control mice injected with PBS. 
healthy individuals, the frequency of HPIV3 neutralizing B cells was only $2 \%$ of HPIV3 preFspecific B cells. As a result, our original strategy of sorting and directly cloning antibodies from individual HPIV3 preF-specific B cells from peripheral blood identified predominantly low-affinity naïve B cells, was laborious, expensive, and inefficient, and yielded only a single neutralizing monoclonal antibody. Therefore, we switched to a higher-throughput neutralization screening strategy for HPIV3 based upon an assay developed for $\mathrm{HIV}^{43}$. This allowed us to scan thousands of individual B cells from peripheral blood, tonsils, and spleens and select only those that produced neutralizing antibodies against HPIV3 for subsequent monoclonal antibody cloning. Using this method, we confirmed the low frequency of HPIV3 preF-specific B cells able to produce neutralizing antibodies and isolated four additional potent HPIV3 neutralizing monoclonal antibodies.

Many human-derived neutralizing monoclonal antibodies to date are based on B cells found in peripheral blood ${ }^{22,43,44}$. We decided to compare the frequency of B cells capable of producing neutralizing antibodies in readily accessible secondary lymphoid organs that might be enriched for B cells that had undergone affinity maturation. We therefore sampled human tonsils from children undergoing elective tonsillectomy and human spleens from previously healthy adult deceased organ donors. Since virtually all children by the age of three demonstrate serologic evidence of infection by parainfluenza virus, we did not need to screen donors for evidence of previous infection $^{26}$. We found that tonsils were significantly enriched with B cells capable of producing HPIV3 neutralizing monoclonal antibodies. Although tonsillectomy is a common procedure and has long been thought to have negligible long-term costs, more recent data suggests tonsillectomy may be associated with increased long-term risks for respiratory infections ${ }^{45}$. Human spleens were also enriched for B cells capable of neutralizing HPIV3, although the magnitude of enrichment was much lower than in tonsils.

The majority of neutralizing antibodies against HPIV3 appeared to target the apex of the F protein in a similar fashion to neutralizing antibodies against $\mathrm{RSV}^{30,46}$. The ability of PI3-E12 to bind the apex of HPIV3 preF in a ratio of $1 \mathrm{Fab}: 1$ trimer is also reminiscent of the binding mode of VRC26.25, the most potent HIV V1V2-recognizing antibody isolated to date ${ }^{47}$. PI3-E12 showed high specificity for the prefusion conformation of HPIV3 F, unlike the previously isolated apical binding monoclonal antibody PIA174 which bound weakly to the post-fusion conformation. The ability of PIA174 to bind the post-fusion conformation was unexpected since the antigenic site at the apex is unique to the prefusion conformation. In the related fusion protein of RSV, the apical antigenic site consists of an unstructured region and an alpha helix which are displaced by more than $5 \AA$ in the post-fusion conformation $^{48}$. It is possible that PIA174 is able to bind weakly to small stretches of linear epitopes found in both the pre- and post-fusion conformations. Interestingly, the monoclonal antibodies we isolated all utilized different immunoglobulin heavy and light chain alleles. A similar phenomenon was previously described in which human antibodies targeting the receptor binding site of hemagglutinin were found to arise from nearly unrestricted germ-line origins from multiple donors, and as a result viral resistance to one antibody did not confer resistance to all ${ }^{49}$. This suggests a wide variety of evolved solutions to the problem of blocking viral attachment and binding are available in the general population, making this antigenic site an appealing vaccine target ${ }^{50}$.

We focused our efforts on determining the in vivo efficacy of PI3-E12, because it was among the most potent neutralizing antibody against site $\varnothing$. Given the in vitro potency of PI3-E12, we anticipated a low $\mathrm{EC}_{50}$. Similar to palivizumab for RSV, a dose of at least 2.5 $\mathrm{mg} / \mathrm{kg}$ reduced HPIV3 levels in the lungs in virtually all animals. Additionally, $5 \mathrm{mg} / \mathrm{kg}$ of PI3-E12 significantly reduced HPIV3 replication in the nose, in contrast to palivizumab which failed to suppress RSV replication in the nose even at a dose of $8 \mathrm{mg} / \mathrm{kg}{ }^{51,52}$. Given the ability of PI3-E12 to suppress HPIV3 replication in the nose and lungs of immunocompromised animals when given after infection, PI3-E12 could play a role in both prophylaxis or therapy against HPIV3 infections in the HCT population. Testing the in vivo efficacy of potent HPIV3 neutralizing antibodies at additional, later timepoints in cotton rats and non-human primates would provide further insights into the therapeutic window. We have recently described a method of engineering $B$ cells using CRISPR/Cas9 to express palivizumab and conferred protection against RSV in naïve animals by adoptive transfer of these cells ${ }^{53}$. In this revolutionary new age of cellular therapy and immunotherapy against cancer, it is conceivable that B cells could be engineered to produce a variety of protective antibodies against multiple pathogens and transferred along with the stem cell product during transplant as part of treatment for an underlying disease.

\section{MATERIALS AND METHODS \\ Study design}

The size of experimental groups is specified in figure legends. Peripheral blood was obtained by venipuncture from healthy, HIVseronegative adult volunteers enrolled in the Seattle Area Control 
study, which was approved by the Fred Hutchinson Cancer Research Center institutional review board. PBMCs were isolated from whole blood using Accuspin System Histopaque-1077 (Sigma-Aldrich). Institutional review board approval for studies involving human tonsils was obtained from Seattle Children's Hospital. Studies involving human spleens were deemed non-human subjects research since tissue was de-identified, otherwise discarded, and originated from deceased individuals. Tissue fragments were passed through a basket screen, centrifuged at $300 \times \mathrm{g}$ for 7 minutes, incubated with ACK lysis buffer (Thermo Fisher) for 3.5 minutes, resuspended in RPMI (Gibco), and passed through a stacked $500 \mu \mathrm{m}$ and $70 \mu \mathrm{m}$ cell strainer. Cells were resuspended in $10 \%$ dimethylsulfoxide in heatinactivated fetal calf serum (Gibco) and cryopreserved in liquid nitrogen before use.

\section{Cell lines}

293F cells (Thermo Fisher) were cultured in Freestyle 293 media (Thermo Fisher). Vero cells (ATCC CCL-81), LLC-MK2 cells (ATCC CCL-7.1), and HEp-2 (ATCC CCL-23) were cultured in DMEM (Gibco) supplemented with $10 \%$ fetal calf serum and 100 $\mathrm{U} / \mathrm{ml}$ penicillin plus $100 \mu \mathrm{g} / \mathrm{mL}$ streptomycin (Gibco). 3T3 CD40L/IL-2/IL-21 feeder cells were cultured in DMEM supplemented with $10 \%$ fetal calf serum, penicillin and streptomycin, plus $0.4 \mathrm{mg} / \mathrm{mL}$ geneticin as described ${ }^{27}$. Irradiation was performed with 5,000 rads.

\section{Viruses}

Wild-type rHPIV3 was a recombinant version of strain JS (GenBank accession number Z11575) and modified as previously described to express enhanced GFP ${ }^{54}$. Virus was cultured on LLC-MK2 cells and subsequently purified by centrifugation in a discontinuous $30 \% / 60 \%$ sucrose gradient with $0.05 \mathrm{M}$ HEPES and $0.1 \mathrm{M}$ $\mathrm{MgSO}_{4}$ (Sigma-Aldrich) at $120,000 \times g$ for $90 \mathrm{~min}$ at $4^{\circ} \mathrm{C}$. Virus titers were determined by infecting Vero cell monolayers in 24-well plates with serial 10-fold dilutions of virus, overlaying with DMEM containing 4\% methylcellulose (Sigma-Aldrich), and counting fluorescent plaques using a Typhoon scanner at five days postinfection (GE Life Sciences).

\section{Expression and purification of antigens}

Expression plasmids for His-tagged HPIV3 preF and postF antigens are previously described ${ }^{25}$. HPIV3 preF contained the following mutations including two disulfide linkages, Q162C-L168C, I213C-

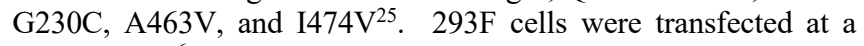
density of $10^{6}$ cells $/ \mathrm{mL}$ in Freestyle 293 media using $1 \mathrm{mg} / \mathrm{mL}$ PEI Max (Polysciences). Transfected cells were cultured for 7 days with gentle shaking at $37^{\circ} \mathrm{C}$. Supernatant was collected by centrifuging cultures at $2,500 \times g$ for 30 minutes followed by filtration through a $0.2 \mu \mathrm{M}$ filter. The clarified supernatant was incubated with $\mathrm{Ni}$ Sepharose beads overnight at $4^{\circ} \mathrm{C}$, followed by washing with wash buffer containing $50 \mathrm{mM}$ Tris, $300 \mathrm{mM} \mathrm{NaCl}$, and $8 \mathrm{mM}$ imidazole. His-tagged protein was eluted with an elution buffer containing 25 $\mathrm{mM}$ Tris, $150 \mathrm{mM} \mathrm{NaCl}$, and $500 \mathrm{mM}$ imidazole. The purified protein was run over a 10/300 Superose 6 size-exclusion column (GE Life Sciences). Fractions containing the trimeric HPIV3 F proteins were pooled and concentrated by centrifugation in an Amicon ultrafiltration unit (Millipore) with a $50 \mathrm{kDa}$ molecular weight cut-off. Two units of biotinylated thrombin (Millipore) were mixed with each $1 \mathrm{mg}$ of protein overnight to cleave off tags, streptavidin agarose (Millipore) was added for another hour to remove thrombin and the cleaved tags, and the mixture was centrifuged through a PVDF filter (Millipore) to remove the streptavidin agarose. The concentrated sample was stored in $50 \%$ glycerol at $-20^{\circ} \mathrm{C}$.

\section{Tetramerization of antigens}

Purified HPIV3 F was biotinylated using an EZ-link Sulfo-NHSLC-Biotinylation kit (Thermo Fisher) using a 1:1.3 molar ratio of biotin to $\mathrm{F}$. Unconjugated biotin was removed by centrifugation using a $50 \mathrm{kDa}$ Amicon Ultra size exclusion column (Millipore). To determine the average number of biotin molecules bound to each molecule of F, streptavidin-PE (ProZyme) was titrated into a fixed amount of biotinylated $\mathrm{F}$ at increasing concentrations and incubated at room temperature for 30 minutes. Samples were run on an SDSPAGE gel (Invitrogen), transferred to nitrocellulose, and incubated with streptavidin-Alexa Fluor 680 (Thermo Fisher) at a dilution of $1: 10,000$ to determine the point at which there was excess biotin available for the streptavidin-Alexa Fluor 680 reagent to bind. Biotinylated $\mathrm{F}$ was mixed with streptavidin-APC at the ratio determined above to fully saturate streptavidin and incubated for 30 $\mathrm{min}$ at room temperature. Unconjugated $\mathrm{F}$ was removed by centrifugation using a $300 \mathrm{~K}$ Nanosep centrifugal device (Pall Corporation). APC/DyLight 755 tetramers were created by mixing F with streptavidin-APC pre-conjugated with DyLight755 (Thermo Fisher) following the manufacturer's instructions. On average, APC/DyLight755 contained 4-8 DyLight molecules per APC. The concentration of each $\mathrm{F}$ tetramer was calculated by measuring the absorbance of APC $(650 \mathrm{~nm}$, extinction coefficient $=0.7$ $\left.\mu \mathrm{M}^{-1} \mathrm{~cm}^{-1}\right)$.

\section{Tetramer enrichment}

$100-200 \times 10^{6}$ frozen PBMCs, $20-50 \times 10^{6}$ frozen tonsil cells, or $40-$ $80 \times 10^{6}$ frozen spleen cells were thawed into DMEM with $10 \%$ fetal calf serum and $100 \mathrm{U} / \mathrm{ml}$ penicillin plus $100 \mu \mathrm{g} / \mathrm{ml}$ streptomycin. Cells were centrifuged and resuspended $50 \mu \mathrm{L}$ of ice-cold FACS buffer composed of PBS and 1\% newborn calf serum (Thermo Fisher). PostF APC/DyLight755 conjugated tetramers were added at a final concentration of $25 \mathrm{nM}$ in the presence of $2 \%$ rat and mouse serum (Thermo Fisher) and incubated at room temperature for $10 \mathrm{~min}$. PreF APC tetramers were then added at a final concentration of $5 \mathrm{nM}$ and incubated on ice for $25 \mathrm{~min}$, followed by a $10 \mathrm{~mL}$ wash with ice-cold FACS buffer. Next, $50 \mu \mathrm{L}$ of anti-APCconjugated microbeads (Miltenyi Biotec) were added and incubated on ice for $30 \mathrm{~min}$, after which $3 \mathrm{~mL}$ of FACS buffer was added and the mixture was passed over a magnetized LS column (Miltenyi Biotec). The column was washed once with $5 \mathrm{~mL}$ ice-cold FACS buffer and then removed from the magnetic field and $5 \mathrm{~mL}$ ice-cold FACS buffer was pushed through the unmagnetized column twice using a plunger to elute the bound cell fraction.

\section{Flow cytometry}

Cells were incubated in $50 \mu \mathrm{L}$ of FACS buffer containing a cocktail of antibodies for 30 minutes on ice prior to washing and analysis on a FACS Aria (BD). Antibodies included anti-IgM FITC (G20-127, BD), anti-CD19 BUV395 (SJ25C1, BD), anti-CD3 BV711 (UCHT1, BD), anti-CD14 BV711 (M0P-9, BD), anti-CD16 BV711 (3G8, BD), anti-CD20 BUV737 (2H7, BD), anti-IgD BV605 (IA6$2, \mathrm{BD})$, and a fixable viability dye (Tonbo Biosciences). Absolute counts within each specimen were calculated by adding a known amount of AccuCheck Counting Beads (Thermo Fisher). B cells were individually sorted into either 1) empty 96-well PCR plates and immediately frozen, or 2) flat-bottom 96-well plates containing feeder cells that had been seeded at a density of 28,600 cells/well one day prior in $100 \mu \mathrm{L}$ of IMDM media (Gibco) containing $10 \%$ fetal calf serum, $100 \mathrm{U} / \mathrm{ml}$ penicillin plus $100 \mu \mathrm{g} / \mathrm{ml}$ streptomycin, and $2.5 \mu \mathrm{g} / \mathrm{mL}$ amphotericin. B cells sorted onto feeder cells were cultured at $37^{\circ} \mathrm{C}$ for 13 days.

\section{ELISA}

Nunc maxsorp 96-well plates (Thermo Fisher) were coated with 100 ng of goat anti-human $\mathrm{F}_{\mathrm{ab}}$ (Jackson ImmunoResearch) for 90 minutes at $4{ }^{\circ} \mathrm{C}$. Wells were washed three times with 1 xDPBS and 
then blocked with1xDPBS containing $1 \%$ bovine serum albumin (Sigma-Aldrich) for one hour at room temperature. Antigen coated plates were incubated with culture supernatants for 90 minutes at $4^{\circ} \mathrm{C}$. A standard curve was generated with serial two-fold dilutions of palivizumab. Wells were washed three times with 1xDPBS followed by a one hour incubation with horse radish peroxidaseconjugated goat anti-human total Ig at a dilution of 1:6000 (Invitrogen). Wells were then washed four times with 1xDPBS followed by a 5-15 minute incubation with TMB substrate (SeraCare). Absorbance was measured at $405 \mathrm{~nm}$ using a Softmax Pro plate reader (Molecular Devices). The concentration of antibody in each sample was determined by reference to the standard curve and dilution factor.

\section{Neutralization assays}

For neutralization screening of culture supernatants, Vero cells were seeded in 96-well flat bottom plates and cultured for 48 hours. After 13 days of culture, $40 \mu \mathrm{L}$ of culture supernatant was mixed with 25 $\mu \mathrm{L}$ of sucrose-purified GFP-HPIV3 diluted to 2,000 plaque forming units $(\mathrm{pfu}) / \mathrm{mL}$ for one hour at $37^{\circ} \mathrm{C}$. Vero cells were then incubated with $50 \mu \mathrm{L}$ of the supernatant/virus mixture for one hour at $37^{\circ} \mathrm{C}$ to allow viral adsorption. Next, each well was overlaid with $100 \mu \mathrm{L}$ DMEM containing 4\% methylcellulose. Fluorescent plaques were counted at five days post-infection using a Typhoon imager. Titers of HPIV3-specific monoclonal antibodies were determined by a $60 \%$ plaque reduction neutralization test $\left(\mathrm{PRNT}_{60}\right)$. Vero cells were seeded in 24-well plates and cultured for 48 hours. Monoclonal antibodies were serially diluted 1:4 in $120 \mu \mathrm{L}$ DMEM and mixed with $120 \mu \mathrm{L}$ of sucrose-purified HPIV3 diluted to $2,000 \mathrm{pfu} / \mathrm{mL}$ for one hour at $37^{\circ} \mathrm{C}$. Vero cells were incubated with $100 \mu \mathrm{L}$ of the antibody/virus mixture for one hour at $37^{\circ} \mathrm{C}$ to allow viral adsorption. Each well was then overlaid with $500 \mu \mathrm{L}$ DMEM containing 4\% methylcellulose. Fluorescent plaques were counted at five days post-infection using a Typhoon imager. PRNT $_{60}$ titers were calculated by linear regression analysis.

\section{$B$ cell receptor sequencing and cloning}

For individual B cells sorted and frozen into empty 96-well PCR plates, reverse transcription (RT) was directly performed after thawing plates using SuperScript IV (Thermo Fisher) as previously described $^{44,55}$. Briefly, $3 \mu \mathrm{L}$ RT reaction mix consisting of $3 \mu \mathrm{L}$ of $50 \mu \mathrm{M}$ random hexamers (Thermo Fisher), $0.8 \mu \mathrm{L}$ of $25 \mathrm{mM}$ deoxyribonucleotide triphosphates (dNTPs; Thermo Fisher), $1 \mu \mathrm{L}$ (20 U) SuperScript IV RT, $0.5 \mu \mathrm{L}$ (20 U) RNaseOUT (Thermo Fisher), $0.6 \mu \mathrm{L}$ of $10 \%$ Igepal (Sigma-Aldrich), and $15 \mu \mathrm{L}$ RNase free water was added to each well containing a single sorted B cell and incubated at $50^{\circ} \mathrm{C}$ for 1 hour. For individual B cells sorted onto feeder cells, supernatant was removed after 13 days of culture, plates were immediately frozen on dry ice, stored at $-80^{\circ} \mathrm{C}$, thawed, and RNA was extracted using the RNeasy Micro Kit (Qiagen). The entire eluate from the RNA extraction was used instead of water in the RT reaction. Following RT, $2 \mu \mathrm{L}$ of cDNA was added to $19 \mu \mathrm{l}$ PCR reaction mix so that the final reaction contained $0.2 \mu \mathrm{L}(0.5 \mathrm{U})$ HotStarTaq Polymerase (Qiagen), $0.075 \mu \mathrm{L}$ of $50 \mu \mathrm{M} 3^{\prime}$ reverse primers, $0.115 \mu \mathrm{L}$ of $50 \mu \mathrm{M} 5^{\prime}$ forward primers, $0.24 \mu \mathrm{L}$ of $25 \mathrm{mM}$ dNTPs, $1.9 \mu \mathrm{L}$ of $10 \mathrm{X}$ buffer (Qiagen), and $16.5 \mu \mathrm{L}$ of water. The PCR program was 50 cycles of $94^{\circ} \mathrm{C}$ for $30 \mathrm{~s}, 57^{\circ} \mathrm{C}$ for $30 \mathrm{~s}$, and $72^{\circ} \mathrm{C}$ for $55 \mathrm{~s}$, followed by $72^{\circ} \mathrm{C}$ for $10 \mathrm{~min}$ for heavy and kappa light chains. The PCR program was 50 cycles of $94^{\circ} \mathrm{C}$ for $30 \mathrm{~s}, 60^{\circ} \mathrm{C}$ for $30 \mathrm{~s}$, and $72^{\circ} \mathrm{C}$ for $55 \mathrm{~s}$, followed by $72^{\circ} \mathrm{C}$ for $10 \mathrm{~min}$ for lambda light chains. After the first round of PCR, $2 \mu \mathrm{L}$ of the PCR product was added to $19 \mu \mathrm{L}$ of the second-round PCR reaction so that the final reaction contained $0.2 \mu \mathrm{L}(0.5 \mathrm{U})$ HotStarTaq Polymerase, $0.075 \mu \mathrm{L}$ of $50 \mu \mathrm{M} 3^{\prime}$ reverse primers, $0.075 \mu \mathrm{L}$ of $50 \mu \mathrm{M} 5^{\prime}$ forward primers, $0.24 \mu \mathrm{L}$ of $25 \mathrm{mM}$ dNTPs, $1.9 \mu \mathrm{L} \mathrm{10X} \mathrm{buffer,} \mathrm{and} 16.5 \mu \mathrm{L}$ of water. PCR programs were the same as the first round of PCR. 4 $\mu \mathrm{L}$ of the PCR product was run on an agarose gel to confirm the presence of a 500-bp heavy chain band or 450-bp light chain band. $5 \mu \mathrm{L}$ from the PCR reactions showing the presence of heavy or light chain amplicons was mixed with $2 \mu \mathrm{L}$ of ExoSAP-IT (Thermo Fisher) and incubated at $37^{\circ} \mathrm{C}$ for $15 \mathrm{~min}$ followed by $80^{\circ} \mathrm{C}$ for 15 min to hydrolyze excess primers and nucleotides. Hydrolyzed second-round PCR products were sequenced by Genewiz with the respective reverse primer used in the $2^{\text {nd }}$ round PCR, and sequences were analyzed using IMGT/V-Quest to identify V, D, and J gene segments. Paired heavy chain VDJ and light chain VJ sequences were cloned into pTT3-derived expression vectors containing the human IgG1, IgK, or IgL constant regions using In-Fusion cloning (Clontech) as previously described ${ }^{56}$.

\section{Monoclonal antibody production}

Secretory IgG was produced by co-transfecting $293 \mathrm{~F}$ cells at a density of $10^{6}$ cells $/ \mathrm{mL}$ with the paired heavy and light chain expression plasmids at a ratio of 1:1 in Freestyle 293 media using 1 $\mathrm{mg} / \mathrm{mL}$ PEI Max. Transfected cells were cultured for 7 days with gentle shaking at $37^{\circ} \mathrm{C}$. Supernatant was collected by centrifuging cultures at $2,500 \times \mathrm{g}$ for 15 minutes followed by filtration through a $0.2 \mu \mathrm{M}$ filter. Clarified supernatants were then incubated with Protein A agarose (Thermo Scientific) followed by washing with IgG binding buffer (Thermo Scientific). Antibodies were eluted with IgG Elution Buffer (Thermo Scientific) into a neutralization buffer containing $1 \mathrm{M}$ Tris-base $\mathrm{pH}$ 9.0. Purified antibody was concentrated and buffer exchanged into 1xDBPS using an Amicon ultrafiltration unit with a $50 \mathrm{kDa}$ molecular weight cut-off.

\section{Bio-Layer Interferometry (BLI)}

BLI assays were performed on the Octet.Red instrument (ForteBio) at room temperature with shaking at $500 \mathrm{rpm}$. Anti-human IgG capture sensors (ForteBio) were loaded in kinetics buffer (PBS with $0.01 \%$ BSA, $0.02 \%$ Tween 20 , and $0.005 \% \mathrm{NaN}_{3}, \mathrm{pH} 7.4$ ) containing $40 \mu \mathrm{g} / \mathrm{mL}$ purified monoclonal antibody for $150 \mathrm{~s}$. After loading, the baseline signal was recorded for $60 \mathrm{~s}$ in kinetics buffer. The sensors were then immersed in kinetics buffer containing $1 \mu \mathrm{M}$ purified HPIV3 F for a $300 \mathrm{~s}$ association step followed by immersion in kinetics buffer for an additional $300 \mathrm{~s}$ dissociation phase. The maximum response was determined by averaging the nanometer shift over the last $5 \mathrm{~s}$ of the association step after subtracting the background signal from each analyte-containing well using a negative control monoclonal antibody at each time point. Curve fitting was performed using a 1:1 binding model and ForteBio data analysis software. For competitive binding assays, penta-His capture sensors (ForteBio) were loaded in kinetics buffer containing $1 \mu \mathrm{M}$ His-tagged HPIV3 F for $300 \mathrm{~s}$. After loading, the baseline signal was recorded for $30 \mathrm{~s}$ in kinetics buffer. The sensors were then immersed for $300 \mathrm{~s}$ in kinetics buffer containing 40 $\mu \mathrm{g} / \mathrm{mL}$ of the first antibody followed by immersion for another 300 $\mathrm{s}$ in kinetics buffer containing $40 \mu \mathrm{g} / \mathrm{mL}$ of the second antibody. Percent competition was determined by dividing the maximum increase in signal of the second antibody in the presence of the first antibody by the maximum signal of the second antibody alone.

\section{Autoreactivity assay}

HEp-2 cells were seeded into 96-well plates at a density of 50,000 cells/well one day prior to fixation with $50 \%$ acetone and $50 \%$ methanol for 10 minutes at $-20^{\circ} \mathrm{C}$. Cells were then permeabilized and blocked with 1xDPBS containing 1\% Triton X-100 (SigmaAldrich) and $1 \%$ bovine serum albumin for 30 minutes at room temperature. $100 \mu \mathrm{L}$ of each monoclonal antibody at $0.1 \mathrm{mg} / \mathrm{mL}$ was added for 30 minutes at room temperature. The $2 \mathrm{~F} 5$ positive control was obtained from the NIH AIDS Reagent Program. Wells were then washed four times in 1xDPBS followed by incubation with goat anti-human IgG Alexa Fluor 594 (Thermo Fisher) at a dilution of 
1:200 in 1xDPBS for 30 minutes at room temperature in the dark. After washing four times with $1 \mathrm{X}$ DPBS, images were acquired using the EVOS Cell Imaging System (Thermo Fisher).

\section{Structural analysis}

\section{$\underline{F}_{a b}$ preparation}

PI3-E12, PI3-C9, and PI3-A12 $\mathrm{F}_{\mathrm{ab}}$ were produced by incubating each $10 \mathrm{mg}$ of $\mathrm{IgG}$ with $10 \mu \mathrm{g}$ of LysC (New England Biolabs) overnight at $37^{\circ} \mathrm{C}$ followed by incubating with protein $\mathrm{A}$ for 1 hour at room temperature. The mixture was then centrifuged through a PVDF filter, concentrated in PBS with a $30 \mathrm{kDa}$ Amicon Ultra size exclusion column, and purified further by SEC using Superdex 200 (GE Healthcare Life Sciences) in $5 \mathrm{mM}$ Hepes and $150 \mathrm{mM} \mathrm{NaCl}$.

\section{Crystallization, data collection, and refinement}

Crystals of PI3-E12 $\mathrm{F}_{\mathrm{ab}}$ were obtained using a NT8 dispensing robot (Formulatrix), and screening was done using commercially available screens (Rigaku Wizard Precipitant Synergy block \#2, Molecular Dimensions Proplex screen HT-96, Hampton Research Crystal Screen HT) by mixing $0.1 \mu \mathrm{L} / 0.1 \mu \mathrm{L}$ (protein/reservoir) by the vapor diffusion method. Crystals used for diffraction data were grown in the following conditions in solution containing $0.2 \mathrm{M}$ ammonium phosphate monobasic, $0.1 \mathrm{M}$ Tris, $\mathrm{pH} 8.5$, and $50 \%$ (+/-) 2-methyl-2,4-pentanediol. Crystals were cryoprotected in Parabar Oil (Hampton). Crystals diffracted to $2.1 \AA$ (Supplemental Table 3). Data was collected on the Fred Hutch X-ray home source and processed using HKL2000 ${ }^{57}$. The structure was solved by molecular replacement using Phaser in CCP4 (Collaborative Computational Project, Number 4), and the $\mathrm{F}_{\mathrm{ab}}$ portion of PDB accession number 6MFT was used as a search model ${ }^{25,58}$. Iterating rounds of structure building and refinement was performed in COOT $^{59}$ and Phenix ${ }^{60}$. Structural figures were made with Pymol ${ }^{61}$ and Chimera ${ }^{62}$.

Negative stain electron microscopy

Complex of PI3-E12 F $\mathrm{ab}_{\mathrm{ab}}+$ HPIV3 preF was formed by mixing both components at a $1: 1$ molar ratio and incubating overnight at $4{ }^{\circ} \mathrm{C}$. Complexes were purified by SEC using Superdex 200 in $5 \mathrm{mM}$ Hepes and $150 \mathrm{mM} \mathrm{NaCl}$ at $\mathrm{pH}$ 7.4. Negative staining was performed using Formvar/carbon grids (Electron Microscopy Sciences) of 300 mesh size. $3 \mu \mathrm{L}$ of HPIV3-PI3-E12 $\mathrm{F}_{\mathrm{ab}}$ complex protein was negatively stained at a concentration of $50 \mathrm{ug} / \mathrm{mL}$ on the grids using $1 \%$ uranyl formate staining solution.

Data were collected using a FEI Tecnai T12 electron microscope operating at $120 \mathrm{keV}$ equipped with a Gatan Ultrascan 4000 CCD camera. The images were collected using an electron dose of $45.05 \mathrm{e}^{-} \AA^{-2}$ and a magnification of $67,000 \times$ that resulted in a pixel size of $1.6 \AA$. The defocus range used was $-1.00 \mu \mathrm{m}$ to -2.00 $\mu \mathrm{m}$. The data was collected using Leginon interface ${ }^{63}$. Image processing was carried out using cisTEM ${ }^{64}$. The final reconstruction was performed using $\sim 12,000$ unbinned particles, refining for 20 iterations with $\mathrm{C} 1$ symmetry applied. PI3-E12 $\mathrm{F}_{\mathrm{ab}}$ (this paper), HPIV3 (PDB ID 6MJZ) ${ }^{25}$ and GCN4 (PDB ID 4DME) ${ }^{65}$ fitting was carried out using the Fit function in Chimera ${ }^{62}$.

\section{Cryo-EM data collection, processing, and model fitting}

The HPIV3 preF protein was incubated with 1.5 molar excess of PI3-E12 $\mathrm{F}_{\mathrm{ab}}$ and the complex was run on SEC in 5mM HEPES (7.5), $150 \mathrm{mM} \mathrm{NaCl}$ buffer. The sample was incubated in $0.085 \mathrm{mM} \mathrm{dn}-$ Dodecyl $\beta$-D-maltoside (DDM) to prevent aggregation during vitrification, followed by vitrification using a chameleon; SPT Labtech, formerly TTP Labtech ${ }^{66-68}$. The grids used were nanowire self-blotting grids. The sample was dispensed onto the nanowire grids using a picoliter piezo dispensing head. A total of $\sim 5 \mathrm{~nL}$ sample, dispensed as $50 \mathrm{pL}$ droplets, was applied in a stripe across each grid, followed by a pause of a few milliseconds, before the grid was plunged into liquid ethane. The grids were imaged using a Titan Krios G3 TEM (FEI) at $300-\mathrm{kV}$ accelerating voltage and liquid nitrogen temperature. The images were recorded (FEI) on a Falcon $3 \mathrm{EC}$ direct electron detector (FEI) operated in electron-counting mode using Serial $\mathrm{EM}^{69}$. The collected frames were motion corrected and ctf estimated using cryoSparc (Punjani et al., 2017). Particles were picked and extracted and further 2D classification, ab initio reconstruction, heterogeneous refinement and final map refinement was performed using cryoSparc ${ }^{70}$. The local resolution of the refined map was estimated using cryoSparc and UCSF Chimera.

The model of HPIV3 preF for fitting into the cryo-EM map was the same as modelled and used while generating PDB $6 \mathrm{MJZ}^{25}$. The crystal structure of PI3-E12 $\mathrm{F}_{\mathrm{ab}}$ was used for fitting into the cryoEM map. The fitting of the HPIV3 preF trimer and $\mathrm{F}_{\mathrm{ab}}$ coordinates to the cryo-EM reconstructed maps were performed using UCSF Chimera $^{62}$. Figures were generated in UCSF Chimera. Map-fitting cross correlations were calculated using the Fit-in-Map feature in UCSF Chimera.

\section{Animals and HPIV3 challenge}

Cotton rat challenge experiments were performed by Sigmovir. Animals in groups of $\mathrm{N}=4-5$ were infected intranasally with $100 \mu \mathrm{L}$ of $10^{5}$ pfu HPIV3. This sample size is consistent with previously published experiments testing the efficacy of RSV monoclonal antibodies in the cotton rat model ${ }^{35,36,51,71}$. Monoclonal antibody was either administered intramuscularly one day prior to infection or one day after infection. Cyclophosphamide $(50 \mathrm{mg} / \mathrm{kg})$ was administered intramuscularly at 21 days prior to infection and readministered every three days for the duration of experiments involving immunosuppression. Nasal turbinates were removed for viral titration by plaque assay at day four post-infection. Lungs were removed for viral titration by plaque assay and histopathology at day four post-infection. Lung and nose homogenates were clarified by centrifugation in EMEM (Gibco). Confluent HEp-2 monolayers were inoculated in duplicate with diluted homogenates in 24-well plates. After incubating for two hours at $37^{\circ} \mathrm{C}$, wells were overlaid with $0.75 \%$ methylcellulose. After four days, the cells were fixed and stained with $0.1 \%$ crystal violet for one hour, and plaques were counted to determine titers as pfu per gram of tissue. Histopathology was performed by inflating dissected lungs with $10 \%$ formalin, immersing in $10 \%$ formalin, embedding in paraffin, sectioning, and staining with hematoxylin and eosin. Slides were scored blind on a $0-4$ severity scale. The scores are subsequently converted to a $0-$ $100 \%$ histopathology scale as previously described ${ }^{35,72}$.

\section{Statistical analysis}

Statistical analysis was performed using GraphPad Prism 7. Pairwise statistical comparisons were performed using unpaired two-tailed t-test. $P<0.05$ was considered statistically significant. Data points from individual samples are displayed.

\section{Data availability}

Sequencing and structural data that support the findings of this study have been deposited in the Protein Data Bank (PDB) and are accessible through PDB accession number 6WRP. All other relevant data are available from the corresponding author on request.

\section{ACKNOWLEDGMENTS}

We thank Julie McElrath for PBMCs from the Seattle Area Control cohort; LifeCenter Northwest for providing de-identified spleen remnants; Ursula Buchholz, Shirin Munir, and Peter Collins for providing the GFP-expressing HPIV3 for neutralization assays; Aliaksandr Druz for expression of preF HPIV3 F; Marina Boukhalova, Kevin Yim, and Jorge Blanco at Sigmovir for their 
expertise with cotton rat experiments; Steve Voght and Jessica Schembri for proof-reading the manuscript; Rebecca Putnam, Paula Culver, Russell Eberts and Laura Yates for administrative support; the Taylor lab for helpful discussions.

\section{FUNDING}

This study was supported by the Vaccine and Infectious Disease Division Faculty Initiative (J.B. and J.T.) and the Joel Meyers Endowment Scholarship (J.B.) from the Fred Hutchinson Cancer Research Center, a New Investigator Award from the American Society for Transplantation and Cellular Therapy (J.B.), and by the National Institutes of Health under award number T32AI118690 (J. B.). Funding was also provided by the Intramural Research Program of the Vaccine Research Center, National Institute of Allergy and Infectious Diseases, National Institute of Health (G.B.E.S.-J and P.D.K.). The content is solely the responsibility of the authors and does not necessarily represent the official views of the National Institutes of Health.

\section{AUTHOR CONTRIBUTIONS}

J.B. conceived the study, designed and conducted the experiments, analyzed the data, and wrote the manuscript. S.S., C.W., J.R. and M.P coordinated and performed the structural analysis. A.M. provided 3T3 CD40L/IL-2/IL-21 cells. R.B. provided spleens. J.P. provided tonsils. G.B.E.S-.J and P.D.K. provided preF-stabilized HPIV3 F. J.T. conceived the study, designed experiments, analyzed the data, and edited the manuscript.

\section{COMPETING INTERESTS}

Work described in this manuscript has been included in a provisional patent application. The authors have no other competing financial interests in relation to the work described.

\section{REFERENCES}

1 Weinberg, G. A. et al. Parainfluenza virus infection of young children: estimates of the population-based burden of hospitalization. J Pediatr 154, 694-699,

doi:10.1016/j.jpeds.2008.11.034 (2009).

2 Karron, R. A. et al. Identification of a recombinant live attenuated respiratory syncytial virus vaccine candidate that is highly attenuated in infants. J Infect Dis 191, 1093-1104, doi:10.1086/427813 (2005).

3 Wright, P. F. et al. Evaluation of a live, cold-passaged, temperature-sensitive, respiratory syncytial virus vaccine candidate in infancy. $J$ Infect Dis 182, 1331-1342, doi:10.1086/315859 (2000).

4 Ison, M. G. \& Hirsch, H. H. Community-Acquired Respiratory Viruses in Transplant Patients: Diversity, Impact, Unmet Clinical Needs. Clin Microbiol Rev 32, doi:10.1128/CMR.00042-19 (2019).

5 Boeckh, M. The challenge of respiratory virus infections in hematopoietic cell transplant recipients. $\mathrm{Br} J$

Haematol 143, 455-467, doi:10.1111/j.13652141.2008.07295.x (2008).

6 Renaud, C. et al. Mortality rates of human metapneumovirus and respiratory syncytial virus lower respiratory tract infections in hematopoietic cell transplantation recipients. Biol Blood Marrow Transplant 19, 1220-1226, doi:10.1016/j.bbmt.2013.05.005 (2013).

7 Chemaly, R. F., Shah, D. P. \& Boeckh, M. J. Management of respiratory viral infections in hematopoietic cell transplant recipients and patients with

hematologic malignancies. Clin Infect Dis 59 Suppl 5, S344-351, doi:10.1093/cid/ciu623 (2014).

8
Campbell, A. P. et al. Clinical outcomes associated with respiratory virus detection before allogeneic hematopoietic stem cell transplant. Clin Infect Dis 61, 192-202, doi:10.1093/cid/civ272 (2015).

Hutspardol, S. et al. Significant Transplantation-Related Mortality from Respiratory Virus Infections within the First One Hundred Days in Children after Hematopoietic Stem Cell Transplantation. Biol Blood Marrow Transplant 21, 1802-1807, doi:10.1016/j.bbmt.2015.06.015 (2015). Chu, H. Y., Chin, J., Pollard, J., Zerr, D. M. \& Englund, J. A. Clinical outcomes in outpatient respiratory syncytial virus infection in immunocompromised children. Influenza Other Respir Viruses 10, 205-210, doi:10.1111/irv.12375 (2016).

Boonyaratanakornkit, J. et al. Predictive Value of Respiratory Viral Detection in the Upper Respiratory Tract for Infection of the Lower Respiratory Tract with Hematopoietic Stem Cell Transplantation. J Infect Dis, doi:10.1093/infdis/jiz470 (2019).

Erard, V. et al. Airflow decline after myeloablative allogeneic hematopoietic cell transplantation: the role of community respiratory viruses. J Infect Dis 193, 16191625, doi:10.1086/504268 (2006).

Peck, A. J. et al. Respiratory virus infection among hematopoietic cell transplant recipients: evidence for asymptomatic parainfluenza virus infection. Blood 110, 1681-1688, doi:10.1182/blood-2006-12-060343 (2007). Shah, D. P., Shah, P. K., Azzi, J. M. \& Chemaly, R. F. Parainfluenza virus infections in hematopoietic cell transplant recipients and hematologic malignancy patients: A systematic review. Cancer Lett 370, 358-364, doi:10.1016/j.canlet.2015.11.014 (2016).

Glezen, W. P., Taber, L. H., Frank, A. L. \& Kasel, J. A. Risk of primary infection and reinfection with respiratory syncytial virus. Am J Dis Child 140, 543-546 (1986).

Habibi, M. S. et al. Impaired Antibody-mediated Protection and Defective IgA B-Cell Memory in Experimental Infection of Adults with Respiratory Syncytial Virus. Am J Respir Crit Care Med 191, 10401049, doi:10.1164/rccm.201412-2256OC (2015). Hall, C. B., Walsh, E. E., Long, C. E. \& Schnabel, K. C. Immunity to and frequency of reinfection with respiratory syncytial virus. J Infect Dis 163, 693-698 (1991).

Hampson, A. W., Osterhaus, A. D., Pervikov, Y.\& Kieny, M. P. Report of the second meeting on the development of influenza vaccines that induce broadspectrum and long-lasting immune responses, World Health Organization, Geneva, Switzerland, 6-7 December 2005. Vaccine 24, 4897-4900, doi:10.1016/j.vaccine.2006.03.035 (2006).

Cox, M. M., Patriarca, P. A. \& Treanor, J. FluBlok, a recombinant hemagglutinin influenza vaccine. Influenza Other Respir Viruses 2, 211-219, doi:10.1111/j.17502659.2008.00053.x (2008).

Johnson, S. et al. Development of a humanized monoclonal antibody (MEDI-493) with potent in vitro and in vivo activity against respiratory syncytial virus. $J$ Infect Dis 176, 1215-1224, doi:10.1086/514115 (1997). Ngwuta, J. O. et al. Prefusion F-specific antibodies determine the magnitude of RSV neutralizing activity in 
human sera. Sci Transl Med 7, 309ra162, doi:10.1126/scitranslmed.aac4241 (2015). Gilman, M. S. et al. Rapid profiling of RSV antibody repertoires from the memory B cells of naturally infected adult donors. Sci Immunol 1, doi:10.1126/sciimmunol.aaj1879 (2016).

23 Yin, H. S., Paterson, R. G., Wen, X., Lamb, R. A. \& Jardetzky, T. S. Structure of the uncleaved ectodomain of the paramyxovirus (hPIV3) fusion protein. Proc Natl Acad Sci U S A 102, 9288-9293, doi:10.1073/pnas.0503989102 (2005). Moscona, A. Interaction of human parainfluenza virus type 3 with the host cell surface. Pediatr Infect Dis J 16, 917-924, doi:10.1097/00006454-199710000-00003 (1997). Stewart-Jones, G. B. E. et al. Structure-based design of a quadrivalent fusion glycoprotein vaccine for human parainfluenza virus types 1-4. Proc Natl Acad Sci U S A 115, 12265-12270, doi:10.1073/pnas.1811980115 (2018).

26 Henrickson, K. J. Parainfluenza viruses. Clin Microbiol Rev 16, 242-264, doi:10.1128/cmr.16.2.242-264.2003 (2003).

27 Whaley, R. E. et al. Generation of a cost-effective cell line for support of high-throughput isolation of primary human B cells and monoclonal neutralizing antibodies. $J$ Immunol Methods, 112901, doi:10.1016/j.jim.2020.112901 (2020). Steach, H. R. et al. Cross-Reactivity with Self-Antigen Tunes the Functional Potential of Naive B Cells Specific for Foreign Antigens. J Immunol 204, 498-509, doi:10.4049/jimmunol.1900799 (2020).

Bancroft, T. et al. Detection and activation of HIV broadly neutralizing antibody precursor B cells using anti-idiotypes. J Exp Med 216, 2331-2347, doi:10.1084/jem.20190164 (2019).

30 McLellan, J. S. et al. Structure of RSV fusion glycoprotein trimer bound to a prefusion-specific neutralizing antibody. Science 340, 1113-1117, doi:10.1126/science.1234914 (2013).

31 Battles, M. B. et al. Structure and immunogenicity of pre-fusion-stabilized human metapneumovirus $\mathrm{F}$ glycoprotein. Nat Commun 8, 1528, doi:10.1038/s41467017-01708-9 (2017).

32 Ottolini, M. G. et al. Semi-permissive replication and functional aspects of the immune response in a cotton rat model of human parainfluenza virus type 3 infection. $J$ Gen Virol 77 ( Pt 8), 1739-1743, doi:10.1099/00221317-77-8-1739 (1996).

33 Kirkeby, L., Rasmussen, T. T., Reinholdt, J. \& Kilian, M. Immunoglobulins in nasal secretions of healthy humans: structural integrity of secretory immunoglobulin A1 (IgA1) and occurrence of neutralizing antibodies to IgA1 proteases of nasal bacteria. Clin Diagn Lab Immunol 7, 31-39, doi:10.1128/cdli.7.1.31-39.2000 (2000).

34 Fisher, R. G., Crowe, J. E., Jr., Johnson, T. R., Tang, Y. W. \& Graham, B. S. Passive IgA monoclonal antibody is no more effective than $\operatorname{IgG}$ at protecting mice from mucosal challenge with respiratory syncytial virus. $J$ Infect Dis 180, 1324-1327, doi:10.1086/315037 (1999).

Boukhvalova, M., Blanco, J. C., Falsey, A. R. \& Mond, J. Treatment with novel RSV Ig RI-002 controls viral replication and reduces pulmonary damage in immunocompromised Sigmodon hispidus. Bone Marrow

Transplant 51, 119-126, doi:10.1038/bmt.2015.212 (2016).

Johnson, R. A., Prince, G. A., Suffin, S. C., Horswood, R. L. \& Chanock, R. M. Respiratory syncytial virus infection in cyclophosphamide-treated cotton rats. Infect Immun 37, 369-373, doi:10.1128/IAI.37.1.369-373.1982 (1982).

Ottolini, M. G., Curtis, S. R., Mathews, A., Ottolini, S. R. \& Prince, G. A. Palivizumab is highly effective in suppressing respiratory syncytial virus in an immunosuppressed animal model. Bone Marrow Transplant 29, 117-120, doi:10.1038/sj.bmt.1703326 (2002).

Kohler, G. \& Milstein, C. Continuous cultures of fused cells secreting antibody of predefined specificity. Nature 256, 495-497 (1975).

Carter, P. J. \& Lazar, G. A. Next generation antibody drugs: pursuit of the 'high-hanging fruit'. Nat Rev Drug Discov 17, 197-223, doi:10.1038/nrd.2017.227 (2018). Walker, L. M. \& Burton, D. R. Passive immunotherapy of viral infections: 'super-antibodies' enter the fray. Nat Rev Immunol 18, 297-308, doi:10.1038/nri.2017.148 (2018).

Victora, G. D. \& Wilson, P. C. Germinal center selection and the antibody response to influenza. Cell 163, 545548, doi:10.1016/j.cell.2015.10.004 (2015).

Nair, N. et al. VP4- and VP7-specific antibodies mediate heterotypic immunity to rotavirus in humans. Sci Transl Med 9, doi:10.1126/scitranslmed.aam5434 (2017). Huang, J. et al. Isolation of human monoclonal antibodies from peripheral blood B cells. Nat Protoc 8 , 1907-1915, doi:10.1038/nprot.2013.117 (2013).

$\mathrm{Wu}, \mathrm{X}$. et al. Rational design of envelope identifies broadly neutralizing human monoclonal antibodies to HIV-1. Science 329, 856-861, doi:10.1126/science.1187659 (2010). Byars, S. G., Stearns, S. C. \& Boomsma, J. J. Association of Long-Term Risk of Respiratory, Allergic, and Infectious Diseases With Removal of Adenoids and Tonsils in Childhood. JAMA Otolaryngol Head Neck Surg 144, 594-603, doi:10.1001/jamaoto.2018.0614 (2018).

Graham, B. S. Vaccine development for respiratory syncytial virus. Curr Opin Virol 23, 107-112, doi:10.1016/j.coviro.2017.03.012 (2017). Gorman, J. et al. Structure of Super-Potent Antibody CAP256-VRC26.25 in Complex with HIV-1 Envelope Reveals a Combined Mode of Trimer-Apex Recognition. Cell Rep 31, 107488, doi:10.1016/j.celrep.2020.03.052 (2020).

McLellan, J. S. Neutralizing epitopes on the respiratory syncytial virus fusion glycoprotein. Curr Opin Virol 11, 70-75, doi:10.1016/j.coviro.2015.03.002 (2015). Schmidt, A. G. et al. Viral receptor-binding site antibodies with diverse germline origins. Cell 161, 10261034, doi:10.1016/j.cell.2015.04.028 (2015).

Crowe, J. E., Jr. Principles of Broad and Potent Antiviral Human Antibodies: Insights for Vaccine Design. Cell Host Microbe 22, 193-206, doi:10.1016/j.chom.2017.07.013 (2017).

Zhu, Q. et al. A highly potent extended half-life antibody as a potential RSV vaccine surrogate for all infants. Sci Transl Med 9, doi:10.1126/scitranslmed.aaj1928 (2017). Boukhvalova, M. S., Yim, K. C. \& Blanco, J. Cotton rat model for testing vaccines and antivirals against respiratory syncytial virus. Antivir Chem Chemother 26, 
bioRxiv preprint doi: https://doi.org/10.1101/2020.06.15.153478; this version posted October 30, 2020. The copyright holder for this preprint (which was not certified by peer review) is the author/funder. All rights reserved. No reuse allowed without permission.

2040206618770518, doi:10.1177/2040206618770518 (2018). Moffett, H. F. et al. B cells engineered to express pathogen-specific antibodies protect against infection. Sci Immunol 4, doi:10.1126/sciimmunol.aax0644 (2019). Liu, X. et al. Human parainfluenza virus type 3 expressing the respiratory syncytial virus pre-fusion $\mathrm{F}$ protein modified for virion packaging yields protective intranasal vaccine candidates. PLoS One 15, e0228572, doi:10.1371/journal.pone.0228572 (2020). Tiller, T. et al. Efficient generation of monoclonal antibodies from single human B cells by single cell RT$\mathrm{PCR}$ and expression vector cloning. J Immunol Methods 329, 112-124, doi:10.1016/j.jim.2007.09.017 (2008). McGuire, A. T. et al. Specifically modified Env immunogens activate B-cell precursors of broadly neutralizing HIV-1 antibodies in transgenic mice. Nat Commun 7, 10618, doi:10.1038/ncomms10618 (2016). Otwinowski, Z. \& Minor, W. Processing of X-ray diffraction data collected in oscillation mode. Methods Enzymol 276, 307-326 (1997).

58 Collaborative Computational Project, N. The CCP4 suite: programs for protein crystallography. Acta Crystallogr D Biol Crystallogr 50, 760-763, doi:10.1107/S0907444994003112 (1994). Emsley, P. \& Cowtan, K. Coot: model-building tools for molecular graphics. Acta Crystallogr D Biol Crystallogr 60, 2126-2132, doi:10.1107/S0907444904019158 (2004). Adams, P. D. et al. PHENIX: a comprehensive Pythonbased system for macromolecular structure solution. Acta Crystallogr D Biol Crystallogr 66, 213-221, doi:10.1107/S0907444909052925 (2010).

61 DeLano, W. L. Unraveling hot spots in binding interfaces: progress and challenges. Curr Opin Struct Biol 12, 14-20, doi:10.1016/s0959-440x(02)00283-x (2002).

62 Pettersen, E. F. et al. UCSF Chimera--a visualization system for exploratory research and analysis. J Comput Chem 25, 1605-1612, doi:10.1002/jcc.20084 (2004).

(1)

Suloway, C. et al. Automated molecular microscopy: the new Leginon system. J Struct Biol 151, 41-60, doi:10.1016/j.jsb.2005.03.010 (2005).

Grant, T., Rohou, A. \& Grigorieff, N. cisTEM, userfriendly software for single-particle image processing. Elife 7, doi:10.7554/eLife.35383 (2018).

Oshaben, K. M., Salari, R., McCaslin, D. R., Chong, L. T. \& Horne, W. S. The native GCN4 leucine-zipper domain does not uniquely specify a dimeric oligomerization state. Biochemistry 51, 9581-9591, doi:10.1021/bi301132k (2012).

Razinkov, I. et al. A new method for vitrifying samples for cryoEM. J Struct Biol 195, 190-198, doi:10.1016/j.jsb.2016.06.001 (2016).

Wei, H. et al. Optimizing "self-wicking" nanowire grids. J Struct Biol 202, 170-174, doi:10.1016/j.jsb.2018.01.001 (2018).

Dandey, V. P. et al. Spotiton: New features and applications. J Struct Biol 202, 161-169, doi:10.1016/j.jsb.2018.01.002 (2018).

Mastronarde, D. N. Automated electron microscope tomography using robust prediction of specimen movements. J Struct Biol 152, 36-51, doi:10.1016/j.jsb.2005.07.007 (2005).

Punjani, A., Rubinstein, J. L., Fleet, D. J. \& Brubaker, M. A. cryoSPARC: algorithms for rapid unsupervised cryo-EM structure determination. Nat Methods 14, 290296, doi:10.1038/nmeth.4169 (2017).

$\mathrm{Wu}, \mathrm{H}$. et al. Development of motavizumab, an ultrapotent antibody for the prevention of respiratory syncytial virus infection in the upper and lower respiratory tract. J Mol Biol 368, 652-665, doi:10.1016/j.jmb.2007.02.024 (2007).

Porter, D. D., Prince, G. A., Hemming, V. G. \& Porter, H. G. Pathogenesis of human parainfluenza virus 3 infection in two species of cotton rats: Sigmodon hispidus develops bronchiolitis, while Sigmodon fulviventer develops interstitial pneumonia. J Virol 65, 103-111 (1991). 
bioRxiv preprint doi: https://doi.org/10.1101/2020.06.15.153478; this version posted October 30, 2020. The copyright holder for this preprint (which was not certified by peer review) is the author/funder. All rights reserved. No reuse allowed without permission.

\begin{tabular}{|c|c|c|c|}
\hline \multicolumn{4}{|c|}{$\begin{array}{l}\text { Supplemental Table } 1 . \\
\text { Immunoglobulin gene usage of HPIV3 } \\
\text { preF-binding B cells from the initial } \\
\text { screen of human PBMCs }\end{array}$} \\
\hline $\mathrm{mAb}$ & $\begin{array}{c}\text { Heavy } \\
\text { chain gene }\end{array}$ & $\begin{array}{c}\text { Kappa } \\
\text { chain gene }\end{array}$ & $\begin{array}{l}\text { Lambda } \\
\text { chain gene }\end{array}$ \\
\hline PI3-A2 & $3-15 * 01$ & & I2-14*01 \\
\hline PI3-A3 & $3-11 * 03$ & $3-15 * 01$ & \\
\hline PI3-A10 & $4-31 * 03$ & & $2-14 * 01$ \\
\hline PI3-A12K & $4-39 * 01$ & $4-1 * 01$ & \\
\hline PI3-A12L & $4-39 * 01$ & & $4-69 * 01$ \\
\hline PI3-B1 & $4-59 * 01$ & $3-15 * 01$ & \\
\hline PI3-B7 & $1-18 * 01$ & $3-20 * 01$ & \\
\hline PI3-B8 & $3-21 * 01$ & & $1-40 * 01$ \\
\hline PI3-B9 & $3-20 * 01$ & $1-8 * 01$ & \\
\hline PI3-B10 & $5-51 * 03$ & $2-28 * 01$ & \\
\hline PI3-B11 & $3-21 * 02$ & $1-6^{*} 01$ & \\
\hline PI3-C8 & $3-15 * 01$ & & $3-1 * 01$ \\
\hline PI3-C9 & $3-11 * 03$ & & $2-14 * 01$ \\
\hline PI3-C10 & $3-64 D * 06$ & $2-28 * 01$ & \\
\hline PI3-D2 & $3-11 * 03$ & & $1-44 * 01$ \\
\hline PI3-D5 & $3-20 * 01$ & & $3-25 * 02$ \\
\hline PI3-E2 & $3-66 * 01$ & $1-39 * 01$ & \\
\hline PI3-E6 & $5-51 * 03$ & $3-15 * 01$ & \\
\hline PI3-E8 & $3-20 * 01$ & & $1-40 * 01$ \\
\hline PI3-E9 & $3-20 * 01$ & & $2-14 * 01$ \\
\hline PI3-E12 & $3-11 * 03$ & $2-28 * 01$ & \\
\hline PI3-F6 & $3-11 * 03$ & & $2-14 * 01$ \\
\hline PI3-F11 & $3-23 * 01$ & $4-1 * 01$ & \\
\hline PI3-F12 & $3-15 * 01$ & & $7-46 * 01$ \\
\hline PI3-G7 & $5-51 * 01$ & $1-5^{*} 03$ & \\
\hline PI3-G9 & $3-23 * 01$ & & $2-11 * 01$ \\
\hline
\end{tabular}

Supplemental Table 2. Immunoglobulin gene usage of HPIV3 neutralizing monoclonal antibodies

\begin{tabular}{cccccc}
\hline mAb & $\begin{array}{c}\text { Heavy chain } \\
\text { V Gene }\end{array}$ & $\begin{array}{c}\text { \% Similarity to } \\
\text { Heavy Chain } \\
\text { Germ-line }\end{array}$ & $\begin{array}{c}\text { Kappa } \\
\text { chain V } \\
\text { Gene }\end{array}$ & $\begin{array}{c}\text { Lambda } \\
\text { chain V } \\
\text { Gene }\end{array}$ & $\begin{array}{c}\text { \% Similarity } \\
\text { to Light Chain } \\
\text { Germ-line }\end{array}$ \\
\hline \hline PI3-E12 & $3-11 * 03$ & 93.8 & $2-28 * 01$ & & 96.9 \\
PI3-C9 & $3-11 * 03$ & 96.5 & & $2-14 * 01$ & 98.6 \\
PI3-A3 ${ }^{\mathrm{B}}$ & $3-7 * 01$ & 94.8 & $1-5 * 03$ & & 95.7 \\
PI3-B5 & $5-51 * 01$ & 96.5 & $1-5 * 03$ & & 95 \\
PI3-A10 & $3-30 * 03$ & 90.3 & $3-11 * 01$ & & 94.3 \\
PI3-A12 & $4-30-4 * 01$ & 90.4 & & $1-47 * 01$ & 90.5 \\
PIA174 & $4-59$ & 92.7 & $1-39$ & & 92.5
\end{tabular}

${ }^{A}$ The neutralizing antibody PI3-E12 and the non-neutralizing antibody PI3-C9 were isolated in the initial screen and are shown for comparison. ${ }^{\mathrm{B} N e u t r a l i z i n g}$ monoclonal antibodies isolated from the high-throughput screen of human spleen. Note, PI3-A3, PI3-A10, and PI3-A12 are different from those listed in Supplemental Table 1.

Supplemental Table 3. Data collection and refinement statistics for PI3-E12 Fab

$\begin{array}{cc}\text { Data collection } & \\ \text { Space group } & \mathrm{P} 22_{1} 2_{1} \\ \text { Cell dimensions } & \\ a, b, c(\AA) & 51.031,79.924,99.685 \\ \alpha, \beta, \gamma\left({ }^{\circ}\right) & 90,90,90 \\ \text { Resolution }(\AA) & 50-2.09(2.13-2.09)^{*} \\ R_{\text {sym }} \text { or } R_{\text {merge }} & 0.122(0.404)^{*} \\ I / \mathrm{s} I & 16.01(3.06)^{*} \\ \text { Completeness }(\%) & 98.0(83.8)^{*} \\ \text { Redundancy } & 6.5(4.8)^{*} \\ C C_{1 / 2} & 0.997(0.905)^{*}\end{array}$

\section{Refinement}

Resolution $(\AA)$

No. reflections

$R_{\text {work }} / R_{\text {free }}$

No. atoms

Protein

Water

Ligand

B-factors $\left(\AA^{2}\right)$

Protein

Water

Ligand

$23.62-2.09(2.154-2.09)^{*}$
$24469(2026)^{*}$
$19.60 / 24.97(23.83 / 34.01)^{*}$
3729
3333
338
58
30.24
29.42
33.96
55.66

0.002
0.51
97.46
0.23
2.24

R.m.s deviations

Bond lengths $(\AA)$

Bond angles $\left({ }^{\circ}\right)$

Ramachadran Favored \%

Ramachadran Outliers \%

MolProbity all-atoms clashscore

* Statistics for the highest-resolution shell are shown in parentheses.
6WRP

\section{PDB ID}


bioRxiv preprint doi: https://doi.org/10.1101/2020.06.15.153478; this version posted October 30, 2020. The copyright holder for this preprint (which was not certified by peer review) is the author/funder. All rights reserved. No reuse allowed without permission.

\section{Supplemental Table 4. Cryo-EM data collection and} refinement statistics of HPIV3 preF - PI3-E12 $F_{a b}$

\begin{tabular}{cc}
\hline Data collection & FEI Titan Krios \\
Microscope & 300 \\
Voltage $(\mathrm{kV})$ & 32.782 \\
Electron dose $(\mathrm{e}-/ \AA 2)$ & Falcon 3 DED \\
Detector & 0.415 \\
Pixel size $(\AA)$ & $\sim-1.5-2.7$ \\
Defocus Range $(\mu \mathrm{m})$ & \\
& \\
Reconstruction & Cryosparc \\
Software & 264756 \\
Particles & $\mathrm{C} 1$ \\
Symmetry & 420 \\
Box size & 5.4 \\
Resolution $(\AA)(\mathrm{FSC} 0.143)$ & \\
Refinement & 1688 \\
Protein residues & 6.1 \\
Resolution (FSC 0.5$)$ & \\
R.M.S. deviations & \\
Bond lengths $(\AA)$ & 0.09 \\
Bond angles $(\circ)$ & 2.437 \\
& \\
Validation & 2.62 \\
Molprobity Score & 5.67 \\
Clash score & 6.47 \\
Rotamers outliers $(\%)$ & 14.65 \\
Ramachandran Favored regions $(\%)$ & 2.7 \\
Disallowed regions $(\%)$ & \\
\hline
\end{tabular}

Resolutions are reported according to the FSC0.143 gold-standard criterion. 
bioRxiv preprint doi: https://doi.org/10.1101/2020.06.15.153478; this version posted October 30, 2020. The copyright holder for this preprint (which was not certified by peer review) is the author/funder. All rights reserved. No reuse allowed without permission.

\section{Supplemental Figure 1.}

a

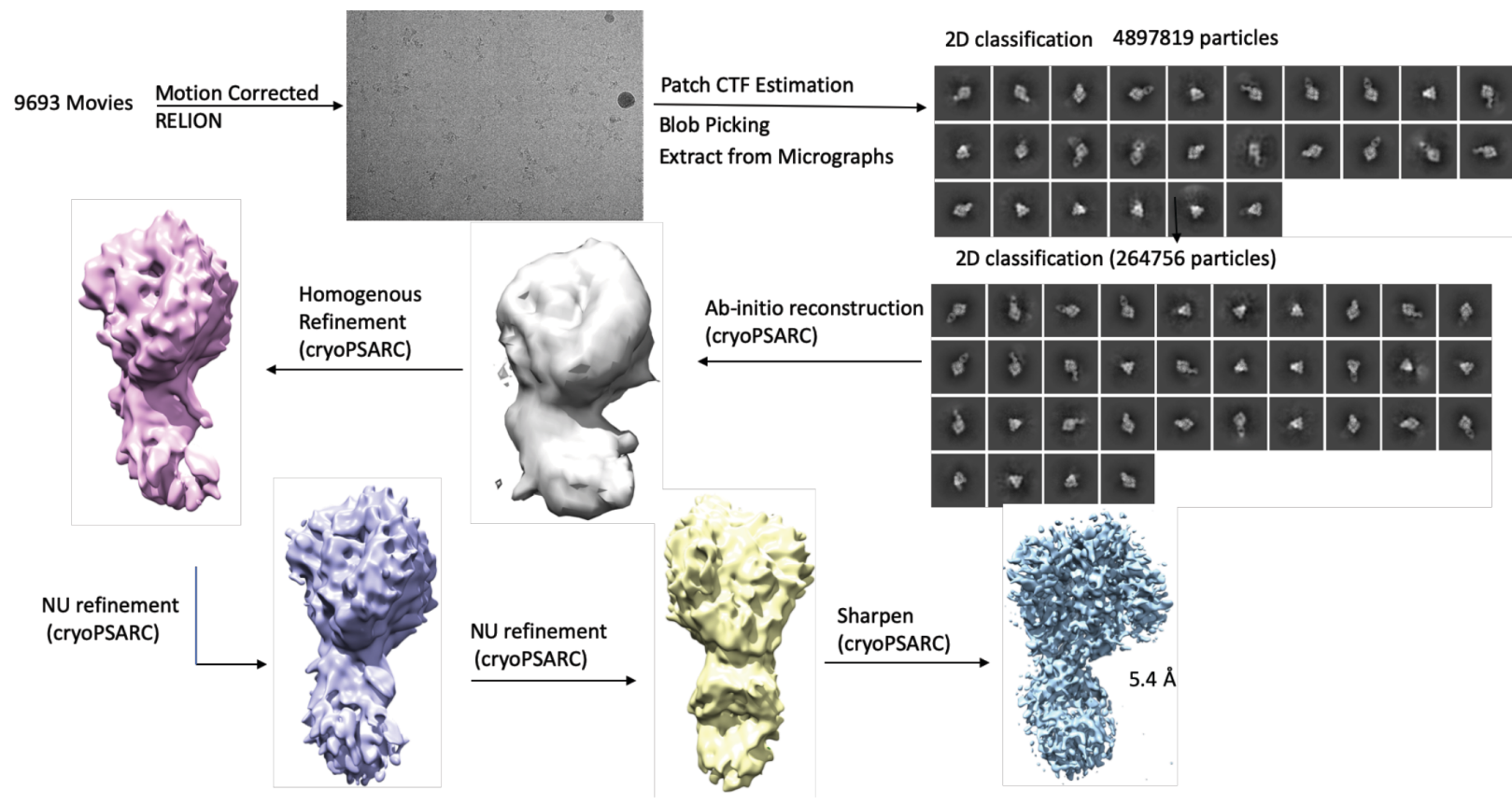

b

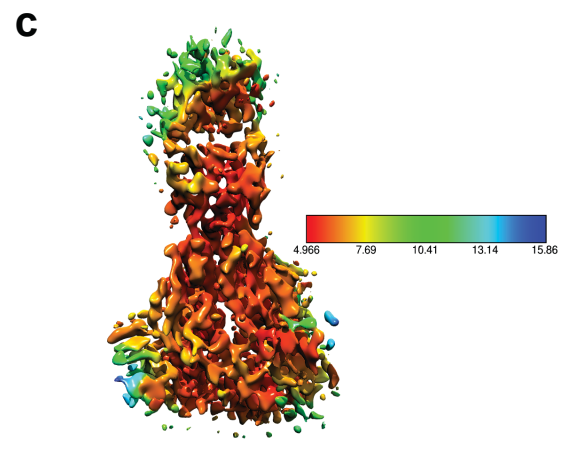

Figure S1. Cryo-EM structural analysis. (a) Cryo-EM workflow. (b) Fourier shell correlation plotted as a function of resolution with resolution reported according to the gold standard $\mathrm{FSC}_{0.143}$ criterion. (c) The complex was most ordered at the core of the HPIV3 F trimer and at its interface with the PI3-E12 Fab, where the cryo-EM map showed a local resolution of 5.0 $\AA$, calculated using Cryopsarc. 